\title{
Article
}

\section{The Spatial Design Marketing Strategy of Global Franchises That Take into Consideration the Characteristics of Modern Consumers-A Study Involving the Global Coffee Companies of Starbucks and Blue Bottle}

\author{
Ji-Eun Kim ${ }^{1}$ and Eun-Soo Park ${ }^{2, *(1)}$ \\ 1 Department of Spatial Culture Design, Kookmin University, Seoul 02707, Korea; jekim@kookmin.ac.kr \\ 2 Department of Architecture, Sahmyook University, Seoul 01795, Korea \\ * Correspondence: espark@syu.ac.kr; Tel.: +82-2-3399-1912; Fax: +82-50-4469-9578
}

\section{check for}

updates

Citation: Kim, J.-E.; Park, E.-S. The Spatial Design Marketing Strategy of Global Franchises That Take into Consideration the Characteristics of Modern Consumers-A Study Involving the Global Coffee Companies of Starbucks and Blue Bottle. Land 2021, 10, 716. https:/ / doi.org/10.3390/land10070716

Academic Editor:

Anna Winiarczyk-Raźniak

Received: 18 May 2021

Accepted: 29 June 2021

Published: 7 July 2021

Publisher's Note: MDPI stays neutral with regard to jurisdictional claims in published maps and institutional affiliations.

Copyright: (c) 2021 by the authors. Licensee MDPI, Basel, Switzerland. This article is an open access article distributed under the terms and conditions of the Creative Commons Attribution (CC BY) license (https:/ / creativecommons.org/licenses/by/ $4.0 /)$.

\begin{abstract}
Coffee shops are evolving into spaces that offer diverse experiences for consumers, with coffee acting as a medium. They are simple venues where people can drink coffee and enjoy and share their cultures with each other; moreover, coffee shops capture the consumers' complex individuality and values. Considering this trend, it is worth looking at the coffee shop in connection with spatial design marketing, as a place that has endless potential to effectively express the needs of modern consumers through spatial identity and story. Accordingly, this study is focused on global coffee franchises because a single brand can control factors other than spatial design, such as coffee price, quality, brand identity, and service. This study looks at global coffee franchises from the spatial design marketing perspective, to examine the value and importance of a space as not only one of the elements of spatial design, but also as a marketing agent. To this end, spatial design marketing will be presented for Starbucks and Blue Bottle, which are the front-runners of the global coffee franchise sector. This study also explores the meaning of directional space, within the global coffee franchises, a meaning that will be transformative in the future. This study is significant in that it derived three spatial marketing characteristics and six strategies that can enhance the spatial value of coffee shops and the experiential value of consumers. This was accomplished through an approach focused on Starbucks and Blue Bottle, the most representative global coffee franchises. Moreover, the presented spatial design marketing strategies are not only applicable to coffee franchises but also to various commercial spatial design fields, and are expected to be used as a business methodology that can satisfy the needs of modern consumers and increase the unique value of their brand.
\end{abstract}

Keywords: spatial design marketing; modern consumers; global coffee franchises; Starbucks; Blue Bottle; marketing strategy

\section{Introduction}

With the development of information and communication along with the popularization of smartphones, the online realm has become stronger, while the influence of offline space has gradually decreased. This is because the meaning of space has diversified as the traditional concept of it was innovatively dismantled by technology, with the beginning of the digital transformation era. However, consumers have started to turn their attention back to the offline space, where they can personally consume and experience culture; they have started to feel the limits of the online environment with the recent imprudent saturation of information. In response to this trend, companies are devising various spatial design marketing ideas to heighten the consumer's loyalty and give special value to their brand. That is to say, consumers are demanding that a space where products are introduced and sold should also provide a new user experience (UX),in accordance with a detailed spatial design marketing strategy that needs to be presented. 
Coffee shops are evolving into venues that offer diverse experiences for consumers, with coffee acting as a medium. They are simply places where people can enjoy coffee and share their cultures with each other; moreover, coffee shops capture the consumers' complex individuality and values. Considering this trend, it is worth looking at the coffee shop in connection with spatial design marketing as a place with endless potential to effectively express the needs of modern consumers through spatial identity and story. Accordingly, this study is focused on global coffee franchises, because a single brand can control factors other than spatial design, such as coffee price, quality, brand identity, and service.

Thus, the authors set out the purpose of the study as follows. This study looks at global coffee franchises from the spatial design marketing perspective, to examine the value and importance of a space as not only one of the elements of spatial design, but also as a marketing agent. To this end, spatial design marketing will be presented regarding the orientation of the spaces for Starbucks and Blue Bottle, which are the front-runners of the global coffee franchise sector. This study also explores the meaning of directional space for the global coffee franchises, which will be transformative in the future.

In order to achieve this goal, this study conducts theoretical research based on literature surveys. It applies a research method that derives characteristics from the researcher's perspective and validates them through case studies. In other words, the type of this study is a theory-based case analysis and strategy presentation.

The research methodology of this study is as follows. First, the definitions and principles of spatial design marketing are summarized through a literature review, and the characteristics of modern consumers, which are important in marketing, will be identified through prior studies.

Second, after studying the definitions and types of coffee shops, the distinct characteristics of global coffee franchises will be established from a spatial design marketing perspective. Based on this analysis, the spatial design marketing elements of global coffee franchises will be identified.

Third, by connecting the derived modern consumer characteristics and the spatial design marketing elements of coffee franchises, this study presents the characteristics of spatial design marketing. Additionally, detailed strategies for effective spatial marketing are identified for each characteristic, and an analysis is conducted on how spatial design marketing strategies are applied to the global coffee franchise front-runners, Starbucks and Blue Bottle.

Fourth, following this analysis, the spatial design marketing strategies of Starbucks and Blue Bottle are summarized and the conclusions are presented.

This study analyzed prior studies to identify the characteristics of modern consumers and the elements of spatial design marketing. This was based upon certain characteristics of spatial design marketing and strategies that are presented to support the logic of the research method. Moreover, by connecting this with analyzing the spatial design marketing strategies of Starbucks and Blue Bottle, representing the "second wave" and "third wave of coffee" - a term established by Trish Rothgeb in the November 2002 newsletter of the Specialty Coffee Association of America (SCAA)'s Roaster's Guild-that place brand value in the space, this study aimed to identify in detail what content is used to induce a positive consumer experience.

\section{Spatial Design Marketing and Characteristics of Modern Consumers}

\subsection{Defining Spatial Design Marketing}

Spatial design marketing is a combination of marketing and the presentation of tangible and intangible spaces that inevitably provide an experience for customers, and mainly aims for cultural sensibility or background as follows Table 1. 
Table 1. Status of prior research related to spatial design marketing.

\begin{tabular}{|c|c|c|}
\hline Researcher & Main Content & Reference \\
\hline Park, Eun A & $\begin{array}{l}\text { This study analyzed experience marketing as an } \\
\text { approach or problem-solving process, in terms of } \\
\text { marketing that is inferred from a combination of } \\
\text { terms of space and marketing and presupposes a } \\
\text { space of analogy and intangible space. }\end{array}$ & $\begin{array}{c}\text { A Case Study of Idle Spatial Regeneration from } \\
\text { The Perspective of Spatial Marketing, Hanyang } \\
\text { Univ. Master's thesis, } 2019\end{array}$ \\
\hline Christian Mikunda & $\begin{array}{l}\text { This study analyzed the ultimate space and reason } \\
\text { space, a space that receives creative power to move } \\
\text { to the next stage of life, not a living space (first } \\
\text { space), labor, or work space (second space). }\end{array}$ & The Third Place, 2015 \\
\hline Kim, Joo Yeon & $\begin{array}{l}\text { This study is about the activities of building an } \\
\text { impression of a business with a space that is a point } \\
\text { of contact with a customer, or expanding and } \\
\text { managing the brand's value experience through the } \\
\text { impression of that space. }\end{array}$ & Space Branding, 2014 \\
\hline Bernd Schmitt & $\begin{array}{l}\text { This study covers a wide range of marketing, from } \\
\text { traditional marketing centered on features and } \\
\text { benefits that are excluded from a space, through } \\
\text { experiential marketing, to consumer experience in } \\
\text { the space. }\end{array}$ & Experiential marketing, 2013 \\
\hline Pak, Sung Sine & $\begin{array}{l}\text { This study studies overall marketing activities that } \\
\text { meet consumer needs directly to the space provided } \\
\text { by the company or enable the enhancement of } \\
\text { corporate and brand images through } \\
\text { space-mediated experience by consumers. }\end{array}$ & $\begin{array}{l}\text { Study on Strategies of Space Design Marketing } \\
\text { and their Effects, Yonsei Univ. Ph.D. thesis, } 2008\end{array}$ \\
\hline Hong, Sung Yong & $\begin{array}{l}\text { Space marketing in this study is a study of how to } \\
\text { utilize space, and it means various economic } \\
\text { activities generated by space utilization. }\end{array}$ & Space Marketing, 2013 \\
\hline
\end{tabular}

It is neither a living space (first space), nor a working space (second space), but one that receives creative energy to move on to the next stage of life-namely, the ultimate space, a space of reason.

The value of marketing is real, but in the realm of abstract conceptual space, it may be correlated with the consumer's perception of value, which includes the terminology of space following a change in the market and the meaning of action [1].In other words, spatial marketing is a combination of tangible and intangible "spatial design," which utilizes space to provide activities demanded by consumers to satisfy them, and "marketing." Under the premise of sensation, emotion, cognition, behavior, relationship, etc., spatial marketing is a form of comprehensive management for customer satisfaction, thus providing pleasure, experience and satisfaction through the value and experience of brand identity, corporate brand image promotion, and diverse cultural and artistic content and new technology [2]. Modern marketing activities focus on how brands, products, technologies, and services can provide special emotional significance to consumers.

Spatial design marketing has various different interpretations and classifications. However, all interpretations share the same underlying theoretical marketing concept: most marketing strategies are focused on human experiences, and that such experiences create awareness and memory. Notably, a repeated experience creates an identity for a particular space [3].

From the spatial marketing perspective, space can be classified as direct marketing or indirect marketing, depending on the company's perspective on space. Direct marketing regards space as a marketing agent for consumption, and space is directly sold or rented to consumers. Key examples include apartments, studio apartments, and stores.

Indirect marketing concerns space as a medium for marketing and can be classified into three large categories. First, there are production spaces used by companies to produce 
goods, including factories and corporate offices. In the past, only efficient systems were considered when constructing production spaces, but modern-day production spaces are designed to embody the identity of the company in the hopes of also gaining additional marketing benefits [4]. Second, there is the consumer space, where produced goods are consumed, which includes shopping malls and experience stores. In the past, consumer spaces were those where the products were displayed in a certain way to promote sales and deliver goods effectively, or endless sales talk was given to induce consumption [5]. The modern-day consumer space carries out spatial marketing by inducing the crowd effect with esthetic spatial design, or by prolonging the amount of time that a consumer lingers in the space by designing a multicultural space. Third, the consumer benefit space is where the identity and values of a company are expressed, or the change in consumer attitude is directly accommodated [6]. A consumer benefit space includes flagship stores or corporate exhibition halls. The consumer benefit spaces are usually located in key districts of big cities, which may not seem to be efficient marketing from a financial perspective, considering the high rent and the fact that not all consumer visits lead to consumption. However, it is essential spatial marketing for modern companies, in that it effectively delivers brand identity and provides brand culture to customers, thus creating a greater added value through interaction with consumers [7]. Figure 1, below, is a diagram that summarizes the types of space from a marketing perspective. Figure 1 is reconstructed based on the literature from the previously introduced direct marketing and indirect marketing research to newly classify types of space from the marketing perspective.

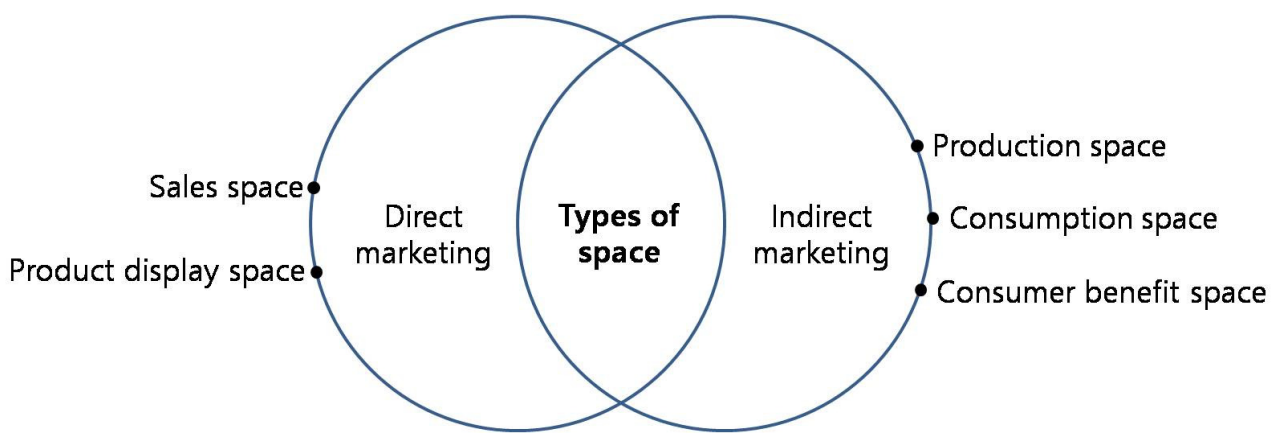

Figure 1. Types of space from the marketing perspective.

\subsection{Principles of Spatial Design Marketing}

Companies that have successfully carried out spatial design marketing have seen their organizations grow and their brand statuses elevated to the next level. Eventually, other companies hurried to further invest in spatial design marketing with detailed principles that led to the emergence of experts, such as space creators and digital cultural space psychologists. They carry out spatial design marketing according to the continuously evolving and advancing consumer styles. Correspondingly, related prior studies present the following four principles for a space that is unique and new, and embodies the essence of the brand: a vanguard, which dominates an image before anyone else increases the power of influence; simplicity, which easily and clearly delivers the message; unexpectedness, surprising people by going beyond expectations; and topicality, a principle that moves hearts with its story [8].

\subsubsection{Vanguard}

The architecture or space for spatial design marketing should have a leading element that differentiates it from the rest. Only when the space can be seen as pioneering by everyone can it dominate the image, and the impact of the message contained in the space be increased [9]. It must aim to be something entirely new, not just something better. However, just because the form of the space is new does not mean that it is a vanguard. To be a vanguard means to be entirely differentiated from all others. Jack Trout said, "The 
easiest way into people's minds is to be 'the first'." For successful spatial design marketing, the space must have a leading position and taste [10].

\subsubsection{Simplicity}

Common sense is the wisdom everyone possesses. So, utilizing the communal memories that everyone has as a common sense for design is a wise approach to spatial design marketing. The common-sense approach is the simplicity with which consumers can understand without special experience or knowledge [11].The city, which is the living space of modern people, is very complicated and rapidly changes. Accordingly, modern people are tormented by excessive stimulation [12]. In such a society with too much communication, modern people need to simplify their minds. Therefore, simplifying complex concepts makes it easier for people to remember things without having to think too much [13].The exact concept of simplicity for spatial design marketing lies in the heart of the message being conveyed. The image must be simplified so that it is easy on the eyes, while experience diversity is needed in the details [14]. If this is achieved, the tension between simplicity and diversity will allow the consumers to fully experience the space with their senses.

\subsubsection{Unexpectedness}

Stimulation in a space greatly affects consumer behavior; it requires an impression of space that induces appropriate actions, to which unexpectedness is key [15]. An unexpected surprise must be provided amidst the simplicity. The positive experience of an unexpected surprise increases the consumers' loyalty to the brand. The surprise is strong pleasure newness and impression yield, and this pleasure creates a positive perception of the brand [16]. Mood, emotion, and immersion are important in understanding consumer satisfaction regarding unexpectedness. Furthermore, mood, emotion, and immersion must be integrated with the identity of the business [17]. This means that the consumer must be able to emotionally empathize with the brand identity that is embodied, in an immersive, unexpected space [18]. The immersion of an unexpectedness experienced in a space has participatory, communicative, amusing, and continuous characteristics [19].

\subsubsection{Topicality}

The main factors of topicality are everything associated with what the consumers may be interested in, from the brand story to the impression of a powerful space [20]. The important thing is that topicality should not be a marketing activity for after the space is created, but rather it should be a story that is prepared as the space is being designed [21]. There are three strategies in creating topicality: familiarity that utilizes memory nostalgia, sharing values communicated through beliefs and significance, and a sense of empathy that appeals to emotion [4]. First, memory nostalgia is connected to familiarity and friendliness, and it is a way to utilize memory images that people have in common in their daily lives, through spatial design. Sensory clues that consumers already recognize lead to intimacy and comfort, and their memories are utilized to create connections with space. Second, the sharing of values is a way to create topicality, by letting the values of business and values of consumers meet in one space. Third, empathy of emotion is a way of creating topicality through a space of remarkable exclamation, and empathy here refers to feeling a connection with the business through a spatial experience.

The following table (Table 2) summarizes the principles of spatial design marketing [8]. 
Table 2. Principles of spatial design marketing.

\begin{tabular}{|c|c|c|}
\hline Strategic Element & Keywords & Detail \\
\hline Vanguard & Differentiation, Preference & $\begin{array}{l}\text { - } \quad \begin{array}{l}\text { Must dominate the image in advance and aim to be the } \\
\text { pioneering original }\end{array} \\
\text { - } \quad \text { Must be absolutely differentiated from other spaces } \\
\text { - } \quad \text { Space must embody vanguard location and preferences }\end{array}$ \\
\hline Simplicity & $\begin{array}{l}\text { Common Sense, } \\
\text { Excess Stimulation, } \\
\text { Various Experience }\end{array}$ & $\begin{array}{ll}\text { - } & \text { Utilize design common sense } \\
\text { - } & \text { Pursue simplicity among overflowing stimulus } \\
\text { - } & \text { Experience of diversity must be in the details while staying simple } \\
\text { - } & \text { Provision of sensible and abundant space through the tension } \\
\text { between simplicity and diversity }\end{array}$ \\
\hline Unexpectedness & $\begin{array}{l}\text { Surprise, Mood, Emotions, } \\
\text { Immersion }\end{array}$ & $\begin{array}{l}\text { - } \quad \text { Provide a surprise by stimulating space } \\
\text { - } \quad \text { It must be a surprise that surpasses expectation within simplicity } \\
\text { - } \quad \text { Must integrate with brand identity through mood, emotions, and } \\
\text { immersion } \\
\text { - Immersion has participatory, communicative, amusing, and } \\
\text { continuous characteristics }\end{array}$ \\
\hline Topicality & $\begin{array}{l}\text { Memory Nostalgia, Sharing } \\
\text { Values, Empathy of Emotions }\end{array}$ & $\begin{array}{l}\text { - Must be prepared as the space is being designed } \\
\text { - } \quad \text { Memory nostalgia: use of familiar memory images in space } \\
\text { - } \quad \text { Sharing values: the values of business meet the values of consumers } \\
\text { in the space } \\
\text { - Empathy of emotions: making headlines through connectivity }\end{array}$ \\
\hline
\end{tabular}

\subsection{Characteristics of the Modern Consumer}

Identifying consumer characteristics holds great meaning in spatial design marketing. This is because consumer preferences reflect the social standards and maturity of the society they are a part of. Generational discord is directly reflected in the consumers' preferences. So, while the past generation deemed product functionality and benefits as key selling points, modern consumers consider their unique relationship with a product to be more important [22]. Compared to the past generation, modern consumers are often known to be more temperamental, less loyal, more self-absorbed, more socially aware, and more experience-oriented [23]. In other words, the characteristics of modern consumers can be defined by the six factors given below. Modern consumer characteristics can be represented by saturation of information, the preciousness of everyday life, being experience-oriented, the consumption of culture, and emotional solidarity.

Thus, modern consumers have begun to more passionately express their identities and have started searching within the saturated information of the internet via smartphones for brands that have emotional solidarity and are able to represent the culture that the consumers consume. Furthermore, living in the era of emotional consumption, modern consumers prefer locations and brands that create a sense of the preciousness of their everyday lives. They consider the inherent value of cultural consumption from the act of purchasing objects as important and prefer to enjoy various experiences that tell a robust story through the interaction between space, brand, and consumer. As such, when it comes to spatial design marketing, the characteristics of modern consumers are critical and meaningful. Accordingly, this study has derived six characteristics of modern consumers based on preliminary studies, much like that which is presented below in Figure 2 . Figure 2 is reconstructed, based on detailed literature for each feature, to derive the characteristics of the modern consumer. 


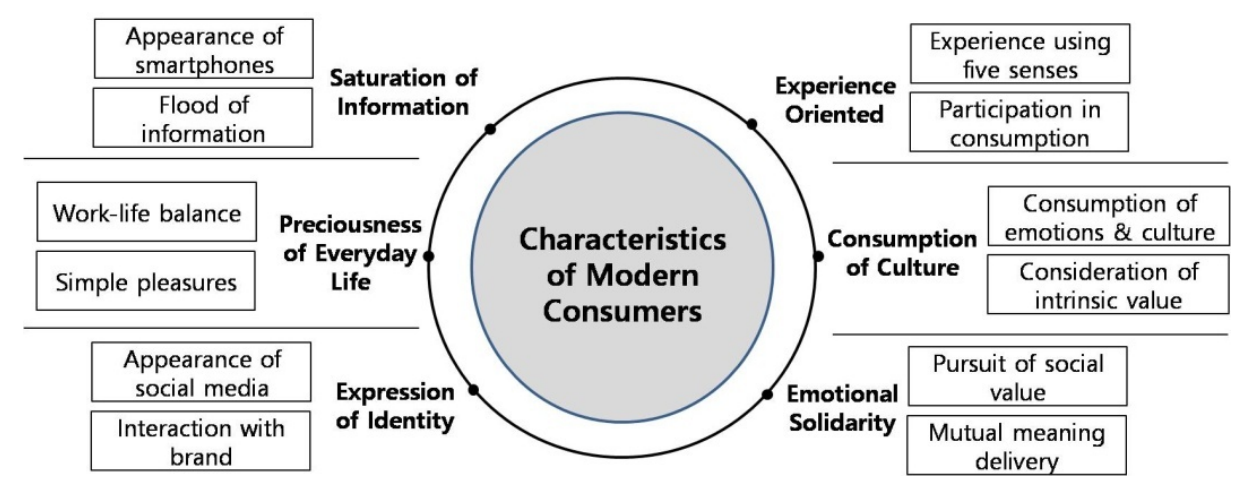

Figure 2. Characteristics of the modern consumer.

\subsubsection{Saturation of Information}

The advent of the smartphone accelerated the development of already fast-growing information technology (IT). In the midst of such saturated information, modern consumers' sensibilities became more meticulous and diverse [24]. Additionally, consumers' accumulated experiences of choice have highly developed their ability to compare products and strengthened their sensibilities, ultimately rendering modern consumers even more particular and sensitive [25]. Thanks to this effect, businesses have become able to focus on marketing that is more intuitive and emotional toward consumers, leading to the shift in focus toward spatial design.

\subsubsection{Preciousness of Everyday Life}

The way modern consumers live in an overly competitive world and the meaning of happiness in a society full of uncertainty and insecurity are becoming diverse [26]. Modern consumers tend to focus more on their current happiness, rather than investing in a successful future [27]. Following shortened work hours and increased leisure time, modern consumers search for practical happiness by consuming the products of their preference or traveling the world to expand their lives [28]. Modern consumers consider moments of their everyday lives to be important and find various and frequent happiness, not in the standards set by society, but in ones they set for themselves. Therefore, to fulfill their happiness within their everyday lives, they comfortably consume.

\subsubsection{Expression of Identity}

Modern consumers satisfy their needs and show their identity and position in society through consumption [29]. Upon finding a brand that reflects their identity, they interact with the brand by consuming and sharing it [28]. Going further, they reinforce their self-perception by consuming their own image as it is reflected by the brand. The act of consumption regarding modern consumers is not only the consumption of commodities but also a means of self-expression.

\subsubsection{Experience Oriented}

When consuming, modern consumers eagerly and adventurously visit spaces to experience a brand first-hand [30]. Spaces are more preferred if they provide diverse experiences of the five senses of sight, smell, hearing, taste, and touch [31]. From the marketing perspective, where businesses have to create consumer-to-product experiences to accelerate the success of their marketing, new experiences are not automatically created during the process of reacting to the stimulus but are induced through the businesses marketing activities [32]. Through such bountiful experiences, the product, space, and brand are able to establish a robust and loyal relationship with the consumer. 


\subsubsection{Consumption of Culture}

To modern consumers, consumption does not merely refer to physical consumption. Consumption in modern society does not simply refer to the need for the consumption of physical things but also embraces emotional and cultural consumption. It has become an important means that brings about modern consumers' consciousness and identity [33]. Canadian scholar Grant McCracken [34] prefaced that there are unique cultural elements included in products and defined a brand as a guarantee of "cultural meaning" for a product. Thus, McCracken claims that businesses not only sell products but also sell the cultural meaning behind the brand to spread the cultural meaning to the consumer, in hopes of sharing a homogeneous culture [35]. As such, modern consumers consume the product as well as the cultural meaning embedded within the product.

\subsubsection{Emotional Solidarity}

Modern consumers avoid one-dimensional consumption that ends at the point of consumption [36]. They prefer to consume products of the best value that generate new values. Although such consumption indicates no more than a personal meaning, modern consumers seek to project and expand their values via the meanings granted through societal connections [26]. In other words, value consumption as sought out by modern consumers is the consumption of an emotional solidarity that focuses on sustainability and social values, steering away from blind consumption [37]. They look for businesses that respect various values, such as sustainable environmental values regarding the disposal of products, local social values that merge harmoniously without disrupting local culture, and the human rights values that respect human rights and do not discriminate against race, wishing to establish emotional solidarity with them. Through such consumption, they express the social values they seek while indirectly taking part in such roles.

\section{Coffee Franchises from the Spatial Design Marketing Perspective}

\subsection{The Development of the Modern Coffee Industry and Global Coffee Franchises}

In the 20th century, coffee shops have developed into franchises, as the concept of capital got added to that of coffee culture [38]. The values of the coffee market were influenced by the definition set forth by the Specialty Coffee Association of America (SCAA) regarding the "first wave of coffee" to the "third wave of coffee" [39].

The first wave of coffee is the history of instant coffee. The first wave of American coffee culture occurred in the 19th century, when Folgers and Maxwell House became household brands, appearing on all American tables. Instant coffee could be mass-produced because of its ease of processing and packaging, and the vacuum-packaging technology discovered by R.W. Hills in 1900 revolutionized the instant coffee culture. The technology of extracting, freeze-drying, and vacuum-packaging coffee allowed consumers to enjoy coffee anytime and anywhere without separate brewing appliances.

The "second wave of coffee" spread with the advent of Starbucks. American consumers were becoming increasingly weary of cheap and low-priced coffee, while the dislike of traditional instant coffee was becoming more prominent. Based in Seattle, Washington, Starbucks began as a coffee shop in 1971 and responded to the demands of consumers by selling fresh coffee beans with information such as the origin of the coffee and the date of manufacture [40]. Along with the espresso machine, invented in the early 1990s, Starbucks was inspired by Italy's long history of café culture and presented its own version of coffee culture and that of "a third space" to consumers ([41]. Retrieved 30 July 2017).Subsequently, consumers could now drink coffee in a space called a "café"; specifically, the coffee was not old, but instead made with freshly pulled espresso. Notably, other Starbucks-inspired coffee brands and franchises began to emerge [42], and this led to the expansion of the movement through espresso variations and local label coffees, such as Starbucks' Grand Decaffeinated Latte [43].

Starbucks has franchise stores all around the world. Following its motto of "a place that sells space, not coffee," its culture is spread through its spaces and is loved by people 
everywhere [44]. As of 2019, Starbucks had opened 32,210 stores in about 80 countries; accordingly, its sales are still steadily increasing. Starbucks' sales for the 2019 fiscal year (October 2018 through September 2019) amounted to USD 26.5 billion (KRW 3.01411 trillion). This figure is 7\% higher than the previous year's USD 24.7 billion [45]. However, Starbucks' advancements did not stop here. To overcome the limitations of the second wave of the coffee industry, Starbucks recently launched its Starbucks Reserve Roastery stores, hoping to expand to the third wave of coffee [46].

The third wave of coffee emerged from the desire for high-end coffee by coffee lovers who grew bored of the taste of standardized coffee [47]. At the heart of the third wave of coffee is the category known as "specialty" [48]. Since the establishment of the American Specialty Coffee Association in 1982, there have been assessments to rate the quality of coffee by adopting certain criteria of objectifying coffee quality [49]. This sparked the emergence of special baristas to satisfy the demand for special, high-quality coffee from coffee lovers. They personally visit coffee bean cultivation sites and check the coffee cultivation process that suits individual preferences [50]. Moving forward from the second wave of coffee, which strove to produce fast and average coffee, it is slowing down in pace to strive for slower coffee, to bring out its natural taste and flavor. The Blue Bottle Coffee Company is the representative brand of the third wave of coffee [51].

Blue Bottle Coffee is by far the leader of the premium coffee shops of the third wave of coffee movement. Others include Intelligentsia Coffee, Stumptown Coffee, and La Colombe Coffee. Blue Bottle pursues extreme coffee quality, and the space of the coffee shop is organized to help consumers solely focus on the taste of the coffee [52]. By drastically excluding factors that may interfere with coffee appreciation and designing the space in a minimalistic fashion, more Blue Bottle fanatics are being created. Currently, there are about 100 Blue Bottle shops worldwide, with their total sales in 2018 reaching 100 billion Korean won (KRW). At the time, Nestlé acquired a $68 \%$ share in Blue Bottle for about USD 425 million (approx. KRW 480 billion) in 2017, while the market value was known to be approximately KRW 700 billion. Having a market value of KRW 700 billion with only 100 shops confirms the strong status of Blue Bottle [53].

\subsection{The Relationshipbetween Spatial Design Marketing and Coffee Franchises}

Following the development of culture and the deepening of consumer knowledge, consumption patterns in modern society also develop and evolve. Modern consumers do not simply consume by weighing efficiency and functionality, as they take a step further to consume culture and pursue value. The ever-increasing pace of life and the emotional deficiency of repetitive daily routines only further deepen this phenomenon. This in turn diversifies and personalizes consumption, leading to an era of emotional consumption in which people deem emotional values more important than functional values [54]. Following this trend, businesses are rushing to attract consumers' vitality through spatial design and to be chosen by consumers.

Businesses that carry out spatial design marketing are adopting their own emotional designs for emotional differentiation as a key concept of spatial design marketing. Through the positioning and robust storytelling of emotional design, spaces are given meaning, capturing the hearts of consumers with the heightened value of space. Soon, the prevalence of spatial marketing continued to coffee shops. More coffee shops are successfully implementing emotional designs, yielding effective spatial marketing, and a new term-"café tour"- has emerged following the culture of searching for coffee shops that satisfy the emotional and cultural consumption needs of consumers. Consumers with an innate desire for emotional diversity are hoping to experience and exchange emotions with unique coffee shops, with which they can identify their lifestyle, and that are different from standardized and planned coffee shops or large coffee franchises [55]. The advent of the third wave of coffee has amplified such change. Large coffee franchises have also designed spatial marketing to not only increase sales but also establish brand identity and a variety of values. New types of coffee shops have steered away from the traditional sense of the 
space as a medium and have become a new type of space representing individual values and expressing individuality.

As the importance of space became more evident, the recent trend of coffee shops is looking at spatial design in different ways. Judging that having high-quality coffee alone would make it difficult to survive in an ever more sophisticated coffee industry, coffee shops look for and develop various features for effective spatial design marketing methods, such as brand identity, the meaning behind a location, and the direction in which to go forward. Coffee shops with fitting spatial design marketing methods have a more distinct brand identity, highlight the esthetics of the space, and provide consumers with a plethora of rich experiences. Given this, a synergy with high-quality coffee is created, thus strengthening the brand of successful coffee shops. When it comes to coffee shops, spatial design marketing is becoming ever more essential and important.

\subsection{Elements of Spatial Design Marketing of Coffee Franchises}

The role of emotional design within spatial design is to identify a human's most basic needs as well as those needs that are difficult to directly express, and then apply them in the design to fulfill people's emotional needs and create a psychological sensation [56]. The coffee shops must effectively provide modern consumers with a space created by emotional design to express brand identity, thereby presenting the consumers with a space that fits their lifestyles and satisfies their needs.

As can be seen in Table 3, based on the analysis of prior studies and the characteristics of modern consumers mentioned in Section 2.3, the following six elements of spatial design marketing were identified: structural, harmonic, identity, solidarity, developmental, and experiential. These elements will be explained through examples of Korean and foreign coffee shops.

Table 3. Elements of spatial marketing based on an analysis of prior studies.

\begin{tabular}{|c|c|}
\hline Keywords Derived from Analysis of Prior Studies & Element of Spatial Design Marketing \\
\hline $\begin{array}{c}\text { Spatial aspect: spatial element, associated image } \\
\text { Environmental aspect: differentiated external appearance } \\
\text { Fundamental element: image, color, form } \\
\text { Functional characteristics: functionality, durability, usability } \\
\text { Spatial characteristics: location, local connections, exterior and interior design }\end{array}$ & Structural Element \\
\hline $\begin{array}{l}\text { Expressive element: original, entertainment, popular, commercial } \\
\text { Emotional element: creating a story, a space that stimulates emotions } \\
\text { Cognitive experience: unique experience, positive brand perception } \\
\text { Stimulation of } 5 \text { senses: surrealism, informativeness }\end{array}$ & Developmental Element \\
\hline $\begin{array}{l}\text { Behavioral experience: creation of lifestyle and brand loyalty } \\
\text { Cultural element: culture, emotions, value, experience } \\
\text { Marketing characteristics: branding, experience, storytelling, and identity } \\
\text { Economic characteristics: identity, efficiency, applicability }\end{array}$ & Identity Element \\
\hline $\begin{array}{l}\text { Environmental characteristics: saving resources, regeneration, and eco-friendly } \\
\text { Value: convenience, culture } \\
\text { Formative characteristics: storytelling, esthetics, and location }\end{array}$ & Solidarity Element \\
\hline $\begin{array}{c}\text { Differentiation: organic vitality, accessibility } \\
\text { Experience: connectivity, interactivity } \\
\text { Sensory experience: stimulation of the five senses, esthetic pleasure }\end{array}$ & Experiential Element \\
\hline $\begin{array}{l}\text { Experience: connectivity, interactivity } \\
\text { Relational experience: interaction, community formation, emotional exchange } \\
\text { Spatial characteristics: location, local connections, exterior and interior design } \\
\text { Social characteristics: regional context, ethics, correlation }\end{array}$ & Harmonious Element \\
\hline
\end{tabular}




\subsubsection{Structural Element}

The structural elements of a coffee shop are the architectural and decorative elements that make up a space, such as the outer walls, columns, movable furniture, lights, and objects. Such spatial design marketing elements can induce a sense of expansion and psychological freedom in consumers, and can grant psychological comfort and spatial uniformity by designing a space using various composition methods and materials (Table 4, Figures 3 and 4).

Table 4. Examples of coffee shops' spatial design marketing associated with structural elements.

\begin{tabular}{cc}
\hline Coffee Shop & Spatial Design Marketing Value \\
\hline $\begin{array}{c}\text { Louverwall (2016, Gyeonggi Province, } \\
\text { South Korea) }\end{array}$ & $\begin{array}{c}\text { This utilizes the curtain-wall and inner sections } \\
\text { (curved walls) and optimizes louver } \\
\text { installation angles to maximize its lighting. }\end{array}$ \\
\hline Sacher Park Cafe (2018, Jerusalem, Israel) [57] & $\begin{array}{c}\text { To rebrand Sacher Park as a modern and } \\
\text { energetic city, an open space was built and } \\
\text { then covered with a circular roof. }\end{array}$ \\
\hline
\end{tabular}

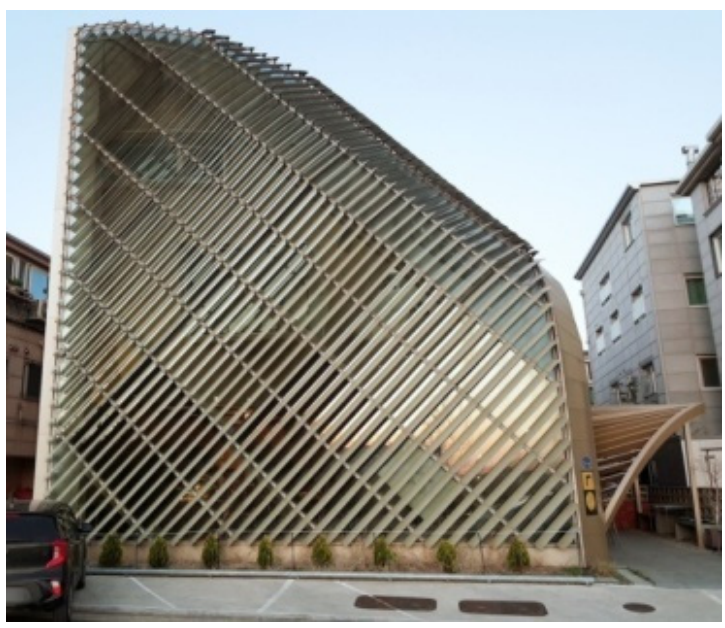

Figure 3. Louverwall (2016, Gyeonggi Province, Korea).

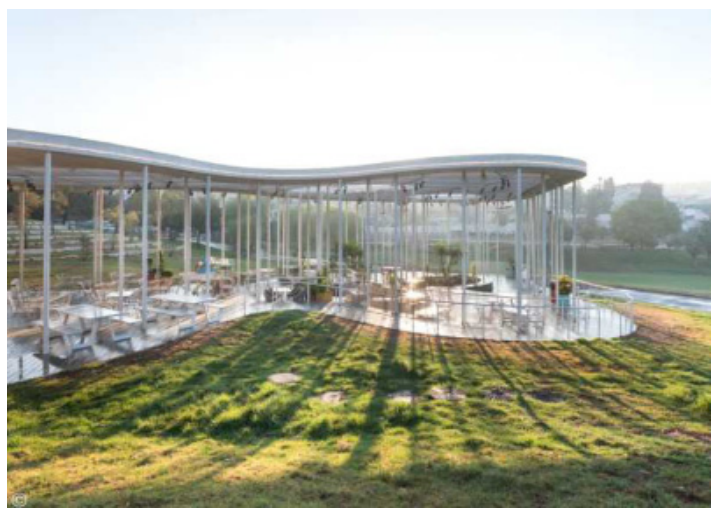

Figure 4. Sacher Park Cafe (2018, Jerusalem, Israel) [57].

\subsubsection{Harmonious Element}

A unique external appearance is one strategic element of spatial design marketing, but it is also important that it be aligned with the regional context. If the space clashes with the surrounding elements, heterogeneity is created in the space, which may negatively influence consumers as it goes against the region's social values. Coffee shops must always 
take into consideration such harmonious elements when choosing and then designing a space (Table 5, Figures 5 and 6).

Table 5. Examples of coffee shops' spatial design marketing associated with harmonious elements.

\begin{tabular}{cc}
\hline Coffee Shop & Spatial Design Marketing Value \\
\hline Onion (2016, Seoul, South Korea) & $\begin{array}{c}\text { This coffee shop remodeled a warehouse, which } \\
\text { created harmony with the surrounding factory } \\
\text { neighborhood and architectural emptiness. }\end{array}$ \\
\hline Ad Lib, Bangkok (2014, Bangkok, Thailand) & $\begin{array}{c}\text { Barley-covered entrance, wooded-effect lobby } \\
\text { interior, and vine-covered walls are in harmony } \\
\text { with Bangkok's surrounding forest. }\end{array}$ \\
\hline
\end{tabular}

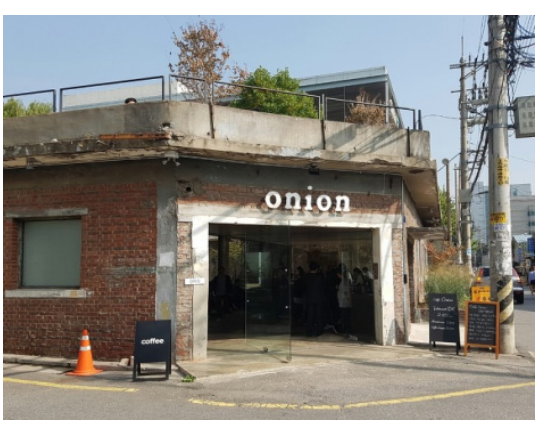

Figure 5. Onion (2016, Seoul, Korea).

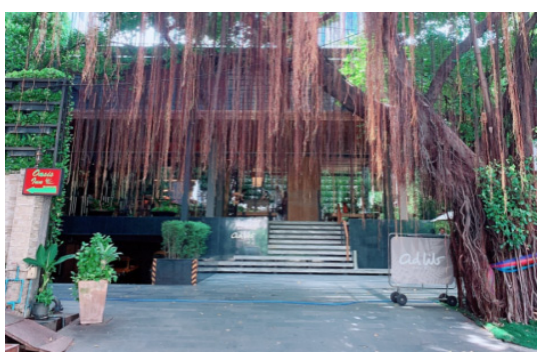

Figure 6. Ad Lib, Bangkok (2014, Bangkok, Thailand).

\subsubsection{Identity Element}

Modern consumers are used to expressing their identity. They express their desires by showing their dispositions through voicing their opinions on social platforms or other personal spaces, while further strengthening their own disposition. Therefore, when modern consumers find a brand that is similar to their orientation, they become loyal to that brand. Key examples are flagship stores or pop-up stores that show the brand's identity in the space, arranging a direct meeting between the brand and the consumers. Coffee shops need to place various branding elements throughout the space to convey brand value to the consumers (Table 6, Figures 7 and 8).

Table 6. Examples of coffee shops' spatial design marketing associated with the identity element.

\begin{tabular}{cc}
\hline Coffee Shop & Spatial Design Marketing Value \\
\hline $\begin{array}{c}\text { In the Mass (2018, Seoul, } \\
\text { South Korea) }\end{array}$ & $\begin{array}{c}\text { This minimal space is vitalized byan orange color that } \\
\text { feels friendly, and a fancy logo gives it a sense of intimacy. }\end{array}$ \\
\hline Café de Flore (1887, Paris, France) & $\begin{array}{c}\text { In using a place visited by artists and intellectuals in the } \\
\text { past as its identity, it provides consumers with a feeling of } \\
\text { participation in that particular culture just by being in the } \\
\text { same space. }\end{array}$ \\
\hline
\end{tabular}




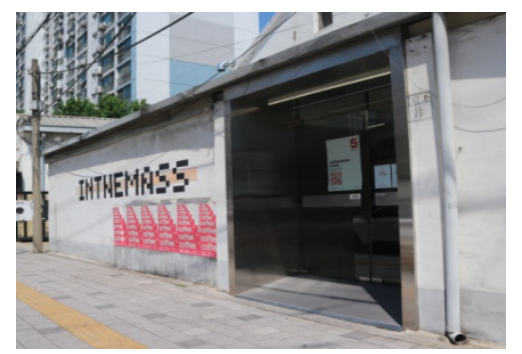

Figure 7. In the Mass (2018, Seoul, Korea).

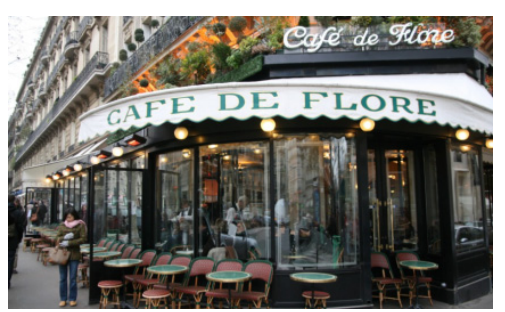

Figure 8. Café de Flore (1887, Paris, France).

\subsubsection{Solidarity Element}

Modern consumers no longer blindly spend their money. They each pursue their own social values that fit with their beliefs, and find brands that pursue the same values as theirs, which empowers that brand by associating themselves with brand value. Modern consumers have begun to think more deeply about and show their social activities more than ever before, which at times leads to situations that are directly connected to sales (Table 7, Figures 9 and 10).

Table 7. Examples of coffee shops' spatial design marketing associated with the solidarity element.

\begin{tabular}{cc}
\hline Coffee Shop & Spatial Design Marketing Value \\
\hline Earth Us (2017, Seoul, South Korea) & $\begin{array}{c}\text { Aims to be a coffee shop free of disposables, operating } \\
\text { under the motto of "What we do for the Earth and for us } \\
\text { is for our own good." }\end{array}$ \\
\hline Café Slow (2001, Tokyo, Japan) [58] & $\begin{array}{c}\text { This was a remodeling of an old bicycle warehouse, and } \\
\text { was designed by mixing only soil, rice straws, and } \\
\text { natural materials for the walls and the floor. It aims to } \\
\text { be a social coffee shop, with organic coffee and } \\
\text { handmade wooden furniture. }\end{array}$ \\
\hline
\end{tabular}

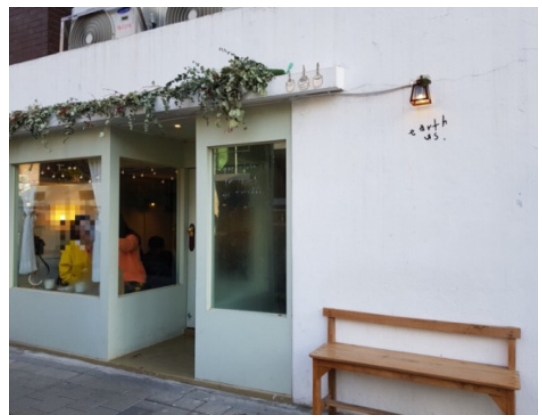

Figure 9. Earth Us (2017, Seoul, Korea). 


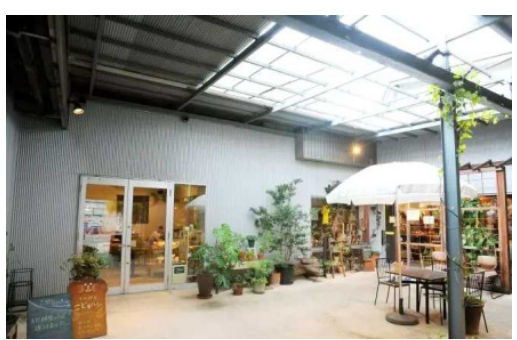

Figure 10. Café Slow (2001, Tokyo, Japan).

\subsubsection{Developmental Element}

The developmental element is there to give a space a story. Effective storytelling, through the development of a theme unique to the brand, can intuitively remind consumers of the brand identity and breathe life into a space, so that it is immediately incorporated into the memory of the consumers (Table 8, Figures 11 and 12).

Table 8. Examples of coffee shops' spatial design marketing associated with the developmental element.

\begin{tabular}{cc}
\hline Coffee Shop & Spatial Design Marketing Value \\
\hline Maxim Plant (2018, Seoul, South Korea) [59] & $\begin{array}{c}\text { An overall storytelling formation, with all the } \\
\text { floors (B2 to 3rd floor) summarily designed to } \\
\text { be a cultural space related to coffee. }\end{array}$ \\
\hline Toranomon Koffee (2014, Tokyo, Japan) & $\begin{array}{c}\text { This features the story of a barista, dressed as a } \\
\text { doctor, diagnosing coffee to consumers in a } \\
\text { modern, square box-shaped store. }\end{array}$ \\
\hline
\end{tabular}

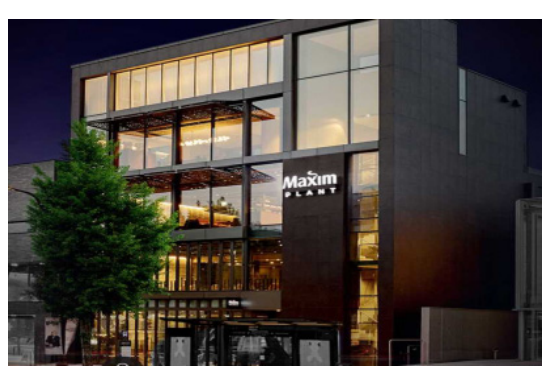

Figure 11. Maxim Plant (2018, Seoul, Korea).

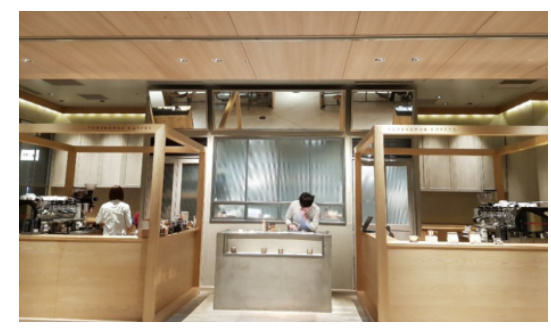

Figure 12. ToranomonKoffee (2014, Tokyo, Japan).

\subsubsection{Experiential Element}

Modern consumers are not reluctant to experience a new space. They personally visit a space in order to be able to actively experience it. Spatial marketing that stimulates the five senses is effective for consumers, approaching them in a different yet colorful way. Each visit will be remembered for a long time by consumers, because memory through the five senses is directly linked to the uniqueness of the product (Table 9, Figures 13 and 14). 
Table 9. Examples of coffee shops' spatial design marketing associated with the experiential element.

\begin{tabular}{cc}
\hline Coffee Shop & Spatial Design Marketing Value \\
\hline Tea Collective (2016, Seoul, South Korea) & $\begin{array}{c}\text { Consumers may select the tea by personally } \\
\text { seeing and smelling the tea, and are given a } \\
\text { personal experience by making their choice of } \\
\text { tea right in front of them. }\end{array}$ \\
\hline Makers CAFE (2014, London, United & $\begin{array}{c}\text { All decorations and props in the shop were } \\
\text { Kingdom) [60] }\end{array}$ \\
the chance to experience the 3D printer. \\
\hline
\end{tabular}

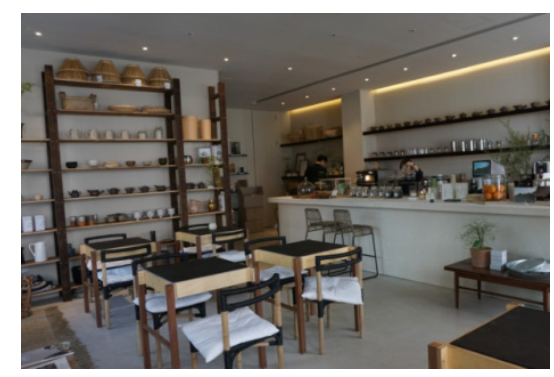

Figure 13. Tea Collective (2016, Seoul, Korea).

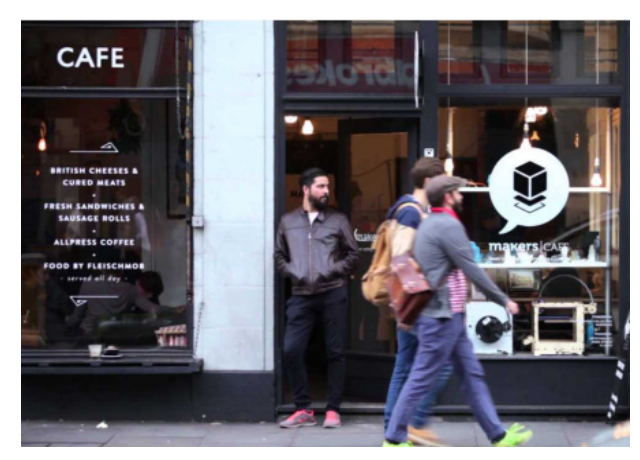

Figure 14. Makers CAFE (2014, London, UK).

\section{Spatial Design Marketing Strategies of Global Coffee Franchises}

\subsection{Characteristics and Strategies of the Spatial Design Marketing of Coffee Franchises}

Based on the characteristics of modern consumers examined in Section 3 and on prior studies [61-63], the six elements of spatial marketing of coffee shops-structural, harmonious, identity, solidarity, developmental, and experiential-were developed and classified into three characteristics of spatial marketing, as shown in Figure 3. Structural and harmonious elements were further developed into esthetic characteristics, identity and solidarity elements into interactive characteristics, and developmental and experiential elements into value characteristics. In Figure 15, the characteristics of modern consumers were analyzed through the relevant references given in Section 2.3. In addition, spatial marketing contents are newly derived elements from the case study concept in Section 3.3. In this process, the characteristics of spatial marketing were newly created by classifying and constructing them into esthetic, interactive, and value characteristics, as shown below. 


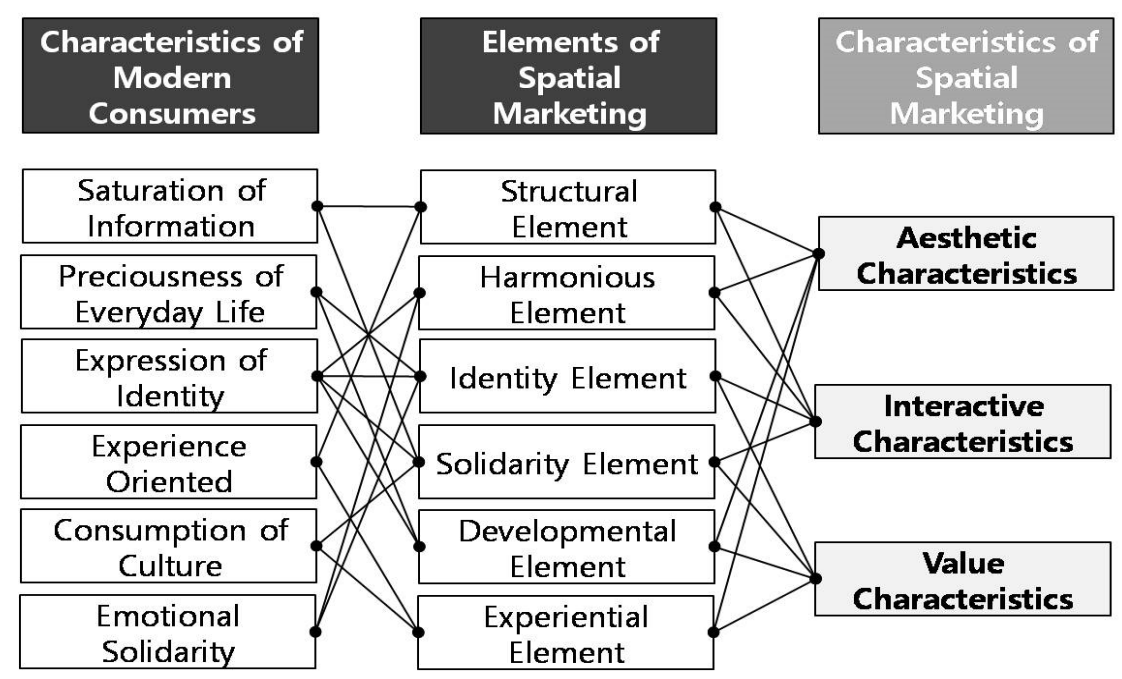

Figure 15. Characteristics of the spatial marketing of coffee shops.

\subsubsection{Esthetic Characteristics}

Space, city, architecture, and interior design are the most influential forms of art in our lives. We work, shop, and practice religion everyday in these spaces. Because it is so tightly woven into our lives and very familiar, we tend to not recognize the existence of such space or not think about its cost, value and utility. Coffee shops with excellent esthetic characteristics successfully grow the business by sensing the role and importance of space [64]. The shops are designed as esthetic spaces, while staying true to the store's individuality. To be able to express the two values of esthetics and individuality well, structural and decorative elements must be used cleverly to design a space in various ways. Esthetic characteristics represent the overall atmosphere of coffee shops, and are the basic elements of space that help the shop achieve its original function and purpose while helping secure its connectivity with the surrounding neighborhood. It is the most basic and morphological structure that safely builds the construction elements of space such as walls, floors, and ceilings, while also limiting the interior sections and area of the space. It is also the decorative element that fills interior spaces-such as furniture, lighting, and objects-and also plays a functional role. Spatial architectural design that reflects esthetic characteristics controls the coffee shop's exterior appearance or overall atmosphere, through such things as architectural materials or objects, so that it seamlessly fits into the surrounding neighborhood and atmosphere. Furthermore, the space must be designed to make it fit with the surrounding environment and not violate the public nature. Therefore, before planning the design, the local characteristics and cultures must be studied in advance. If spatial marketing is effectively carried out using spatial characteristics, the identity of the space will be created, and spatial marketing could further become a means to gain an identity (context) for the region.

\subsubsection{Interactive Characteristics}

Consumers value exchanges with brands; moreover, this is the same with regard to coffee shops. When a consumer is drinking a coffee product, they are also consuming and participating in that brand's identity and the social value it pursues. That is why coffee shops have their brand's iconic logo in the main area of the store, or printed on the take-out coffee cups, and promote the social value they pursue. Brand identity refers to a unique "unified image" that describes a brand. This is then embodied in the brand's philosophy, products, and space, and eventually delivered to consumers. The delivered image may become the brand's strategy for differentiation from thousands of competing brands in the world and become a key factor in increasing brand value. A key example is a flagship store, which is a space that embodies the brand identity. A flagship store for a brand that values identity is not merely a large space to showcase products, but a space that represents 
the brand's philosophy [65]. In addition, the social values pursued by brands are placed throughout the space to be delivered to the consumers through various spatial marketing strategies, or are effectively delivered to the consumers through collaborations with brands that are well known for such social values.

Interactive characteristics relate to delivering spatial marketing value through interaction after connecting brand value with the consumers. For coffee shops, the brand's identity and consumers are directly connected, and interaction is possible. This characteristic is directly linked to branding - a key spatial marketing strategy — and the interaction between the brand and consumers is most important. Modern consumers are used to expressing their orientation and hope to pursue social values by developing their orientation. Thus, if they find a brand that is aligned with their orientation, the relationship with the brand will be close, and strong loyalty will be formed based on emotional solidarity. Coffee shops utilize merchandise or logos, placing related elements throughout the shop to directly and indirectly express brand identity. Additionally, coffee shops further develop their brand identity into social values by utilizing architectural materials or space organization.

\subsubsection{Value Characteristics}

The "third space" is a recent and often-used term that was introduced by Ray Oldenburn in his book, The Great Good Place. The home was defined as the first space, the workplace or school as the second place, and the middle area that is neither the first nor second space as the third space. The third space is neither our home nor workplace, where we spend most of our time, but rather a peaceful, informal public place-a space for privacy, relaxation, and rejuvenation. Recently, as telecommuting has spread due to the COVID-19 pandemic, personal time has increased. Thus, interest in a third space that fills the gap between home and work is rapidly growing. Modern consumers are consuming a company's identity and culture through emotional solidarity with the brand in a third space. Coffee shops are becoming an omni channel where the online and offline communities coexist. Stores are more than just mere spaces to sell products. Thus, they must remind their customers of their differentiated value through spatial marketing with added culture, regardless of the size of the space, and they must design the consumers' experience [66].

Value characteristics are most directly connected to using spatial marketing to blend brand value into space. It is very important to be consistent with the storytelling of a coffee shop's space, or to create a positive perception of the space through the direct or indirect participation of consumers. A coffee shop that has well-applied value characteristics breathes life into the space, and allows the consumers to perceive the space in different ways and sees the shop's space or products being strongly linked to consumer memory. Therefore, the atmosphere of the space must be recreated effectively, and enriched experiences must be provided to the consumers through sensory experience. It can be represented as an extended space where interaction is possible. Spatial marketing with an effective application of cognitive characteristics can have lasting and widespread effects, the purpose of which is to encourage consumers to use this space and to move them by experiencing the space.

Based on the aforementioned six characteristics of modern consumers-saturation of information, treasuring daily life, expressing identity, experience orientation, consuming culture, and emotional solidarity—and the six elements of spatial marketing—structural, harmonious, identity, solidarity, developmental, and experiential — the characteristics of spatial marketing were developed and distinguished into esthetic, interaction, and value characteristics through case studies of each characteristic. From the three characteristics of spatial marketing, this study hopes to derive six spatial marketing strategies: unique design, distinct local characteristics, space of communication, creation of shared value, story composition, and space to experience through the five senses. The characteristics and strategies of spatial marketing are summarized in Table 10. 
Table 10. Spatial Design Marketing Strategies.

\begin{tabular}{|c|c|c|}
\hline $\begin{array}{l}\text { Spatial Design } \\
\text { Marketing Characteristics }\end{array}$ & $\begin{array}{l}\text { Spatial Design } \\
\text { Marketing Strategies }\end{array}$ & Details \\
\hline \multirow[t]{2}{*}{ Esthetic Characteristics } & Unique design & $\begin{array}{l}\text { An effective and original spatial design creates utilization as } \\
\text { well as the ambiance of the space }\end{array}$ \\
\hline & Distinct local characteristics & $\begin{array}{l}\text { Research and traditional analysis are demanded to ensure } \\
\text { that the space is in harmony with the surrounding context. }\end{array}$ \\
\hline \multirow[t]{2}{*}{ Interactive Characteristics } & Space of communication & $\begin{array}{l}\text { Consumers strongly recognize brand identity by consuming } \\
\text { the space as well as the product, and regard the brand and } \\
\text { its consumers as one. }\end{array}$ \\
\hline & Creation of shared value & $\begin{array}{l}\text { Consumers express their presence and identity by sharing } \\
\text { social values. }\end{array}$ \\
\hline \multirow[t]{2}{*}{ Value Characteristics } & Story composition & $\begin{array}{l}\text { Breathes life into the space while ingraining it into the } \\
\text { memory through repeated storytelling. }\end{array}$ \\
\hline & $\begin{array}{l}\text { Space to experience through the } \\
\text { five senses }\end{array}$ & $\begin{array}{l}\text { Induces the direct and indirect experience of consumers by } \\
\text { creating a space that stimulates all five senses. }\end{array}$ \\
\hline
\end{tabular}

\subsection{Strategies of the Spatial Design Marketing of Global Coffee Franchises of Starbucks and} Blue Bottle

This study analyzed the strategies of spatial design marketing derived above, through case studies of two top coffee franchises. This primarily involved Starbucks, the representative franchise of the "second wave" of coffee, and Blue Bottle, the representative franchise of the "third wave" of coffee. Notably, these two companies have most effectively carried out spatial design marketing.

\subsubsection{Unique Design}

The exterior glass walls, which are the most used structural element by Starbucks, are a design product that reflects the preference of its primary consumers-those in their twenties and thirties-for bright places with good lighting, and their psychology and behavior patterns, in which they do not mind revealing themselves (Figure 16). Moreover, Starbucks is the only coffee shop that does not have a vibrating bell system. The usual consumer path in a coffee shop is entrance-register-seat-exit, but that is not the case for Starbucks. After you order at the register, you linger about the premises, checking out the showcased Starbucks MD products, or studying the seasonal menu that is generally displayed on the menu above the register (Figure 17). Starbucks carries out spatial marketing well as a decorative element, using mugs and furniture to strengthen the unity of the Starbucks space. Furthermore, with soft and warm lighting in the space, Starbucks creates an intimate and comfortable atmosphere, helping consumers who have come to experience the space achieve this feeling. 


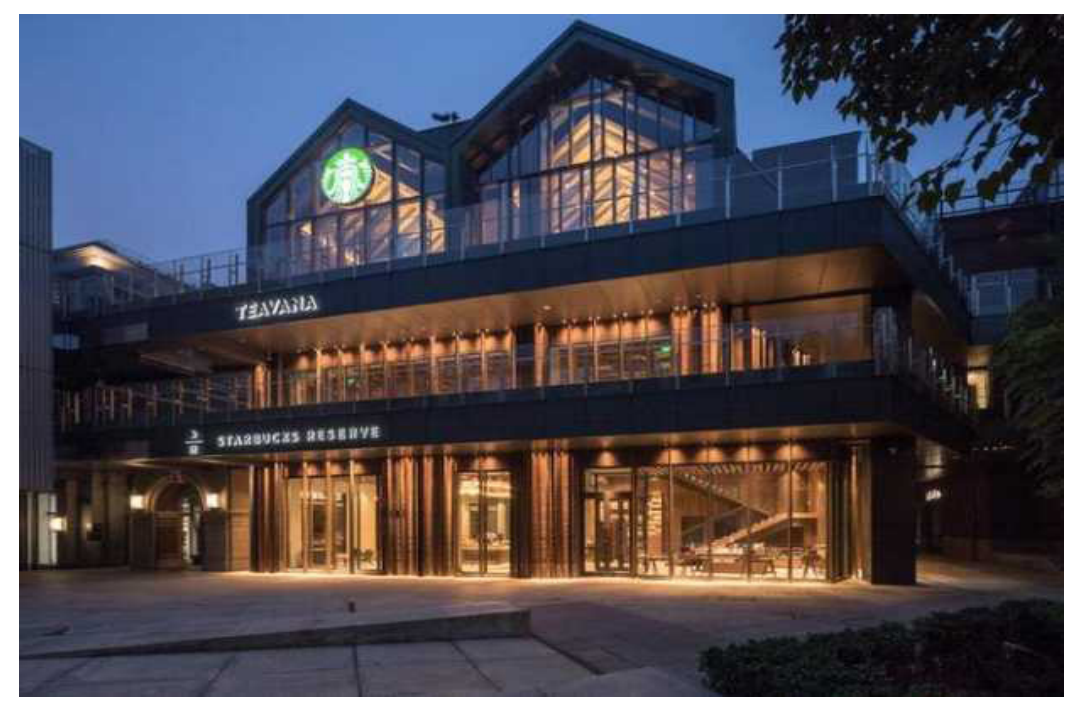

Figure 16. Starbucks Beijing flagship store [67].

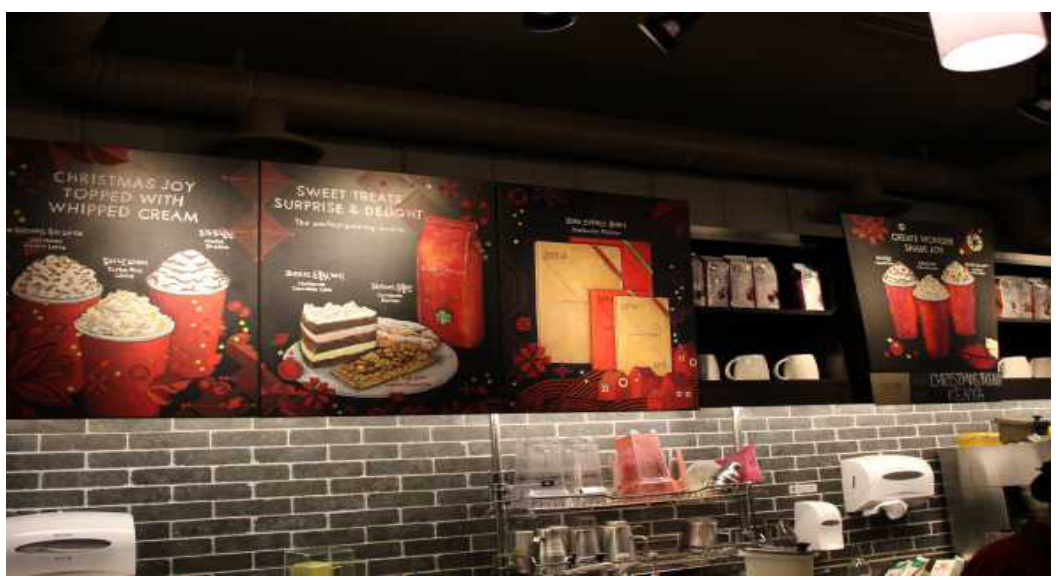

Figure 17. Starbucks'seasonal menu [68].

Blue Bottle began to draw attention with its "architectural emptiness" rather than "architectural fullness." Although the material and furniture that make up the space differ for each store, the achromatic background with the striking blue logo maintains a common naturalness throughout its stores. For example, the unpatterned materials used for the floors are the result of pursuing such naturalness [69]. In addition, for the ultimate coffee taste, which is the core value of Blue Bottle, the interior space of the stores is designed as simply and minimally as possible. The coffee bar and register do not have any objects that interfere with the line of vision, and minimalistic furniture is used, so that the consumers can wholly focus on the coffee itself (Figure 18). Moreover, single seats, double seats, group seats, and bar seats are prepared, so that whoever walks in feels welcome. The different table heights are intriguing when seen from outside, and it is architecturally impressive as well (Figure 19). Furthermore, by maximizing the space between tables, consumers can focus more on tasting coffee rather than staying. The Blue Bottle store in Los Angeles, California reflects these points very well. By properly utilizing the local sunny weather, the store is designed so that the interior can be seen through large windows. It feels comfortable, and a simple and clear flow for the consumers is set, so that they intuitively and completely understand everything about coffee. The register is also placed near the door, so that you see the barista and feel welcomed as soon as you set foot in the shop. 


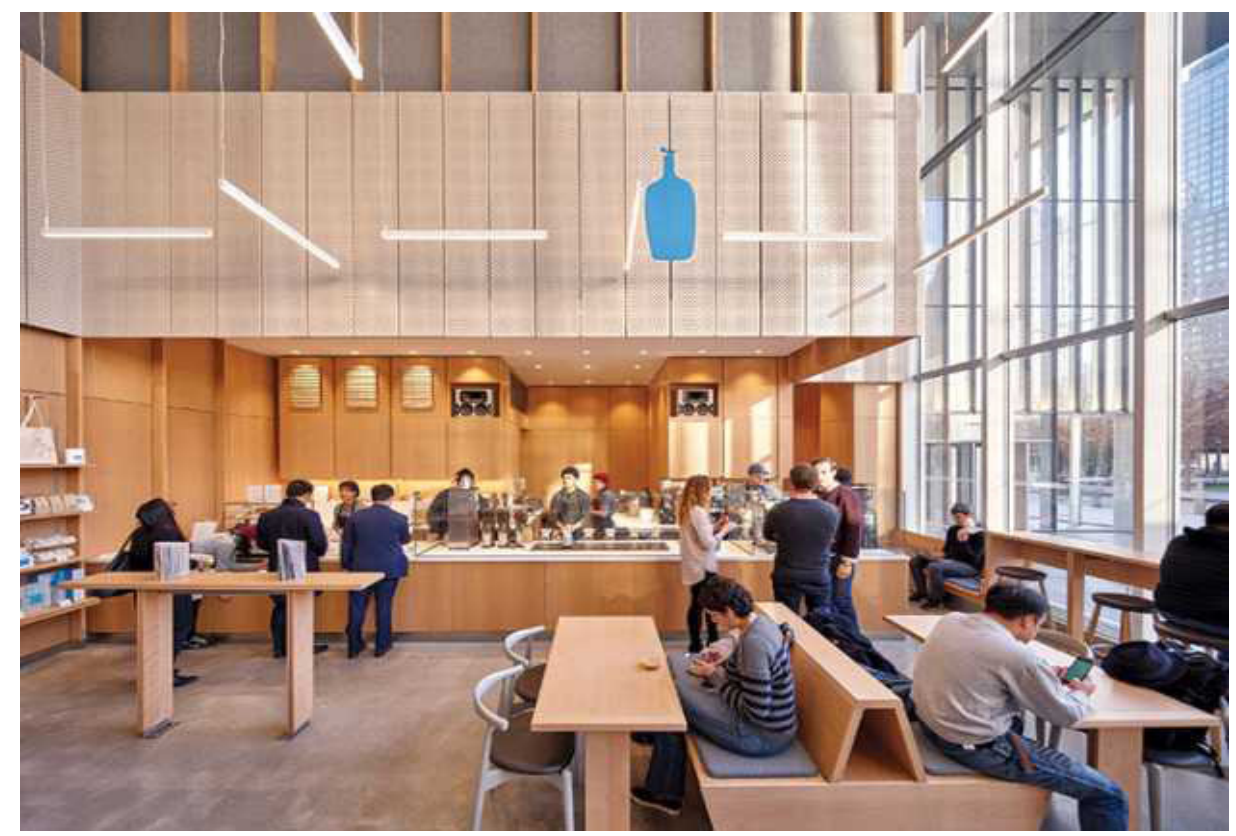

Figure 18. The minimal spatial design unique to Blue Bottle.

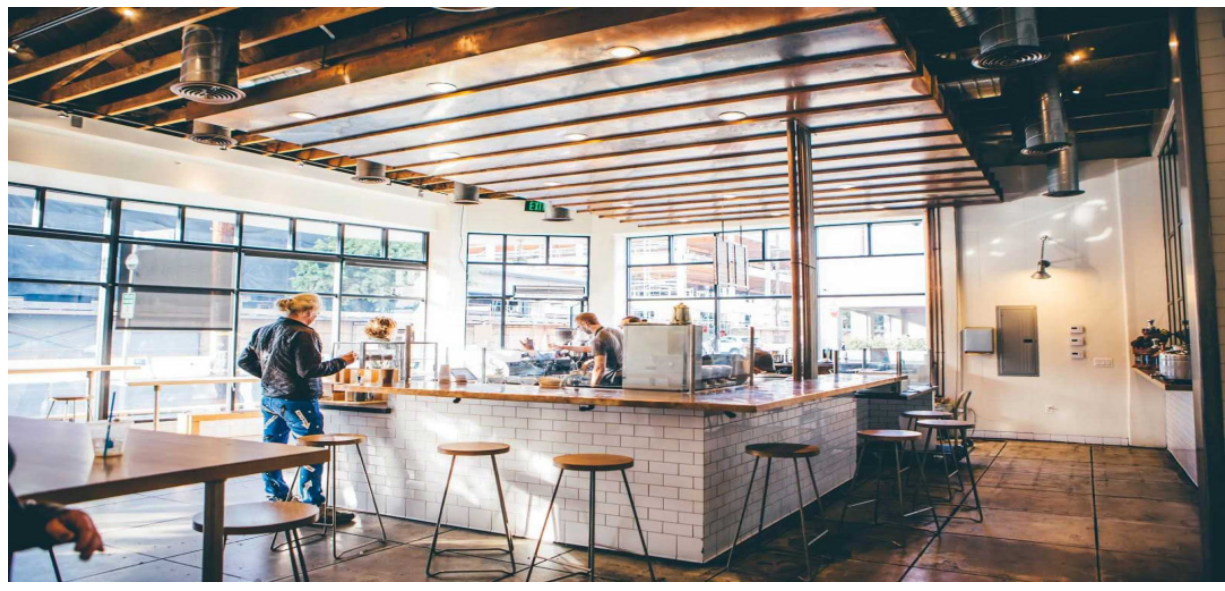

Figure 19. Blue Bottle design utilizing lighting effects through large windows [70].

\subsubsection{Distinct Local Characteristics}

Starbucks emphasizes harmony with the local culture without losing its inherent identity. It is widely known that Starbucks is very particular about its design approach. A new store is designed by combining the standardized global interior design requirements set by the Starbucks headquarters, along with the local design. During this process, although it is difficult to reflect local characteristics, the Starbucks design team studies the location and historical significance of the region, every time the team visits the store after the contract is signed, and then combines it with the store's design. As a result, the Starbucks at MungyeongSaejae, a historical tourist spot in Korea, is built in the style of the exterior of ahanok (traditional Korean house) to highlight the historical significance of the region, and designers added sedentary tables in consideration of consumer families, such as the elderly and children, who are visiting the tourist spot (Figure 20). Additionally, the Starbucks at JejuSeogwipo has a Jeongnang, which means a door in Jeju's traditional culture, while the Starbucks at SogongroBukchang has a gold signboard to represent Sogong-dong, which literally means the "little princess's neighborhood", since that neighborhood is where King Taejong of Josean's second daughter, Princess Gyeongjeong, lived. The Starbucks in Kawagoe, Japan, was designed to reflect culture and architecture style (Figure 21). 
Designing a store that blends traditional architecture and art rooted in the Kawagoe village stemmed from the desire to connect with the community and to have consumers feel an attachment to the space. The consumers feel close to the brand through spaces where they can naturally experience it. The brand will continue to create strategies to increase contact with consumers, through which the consumers' sense of closeness and preference toward the brand can be increased [71].

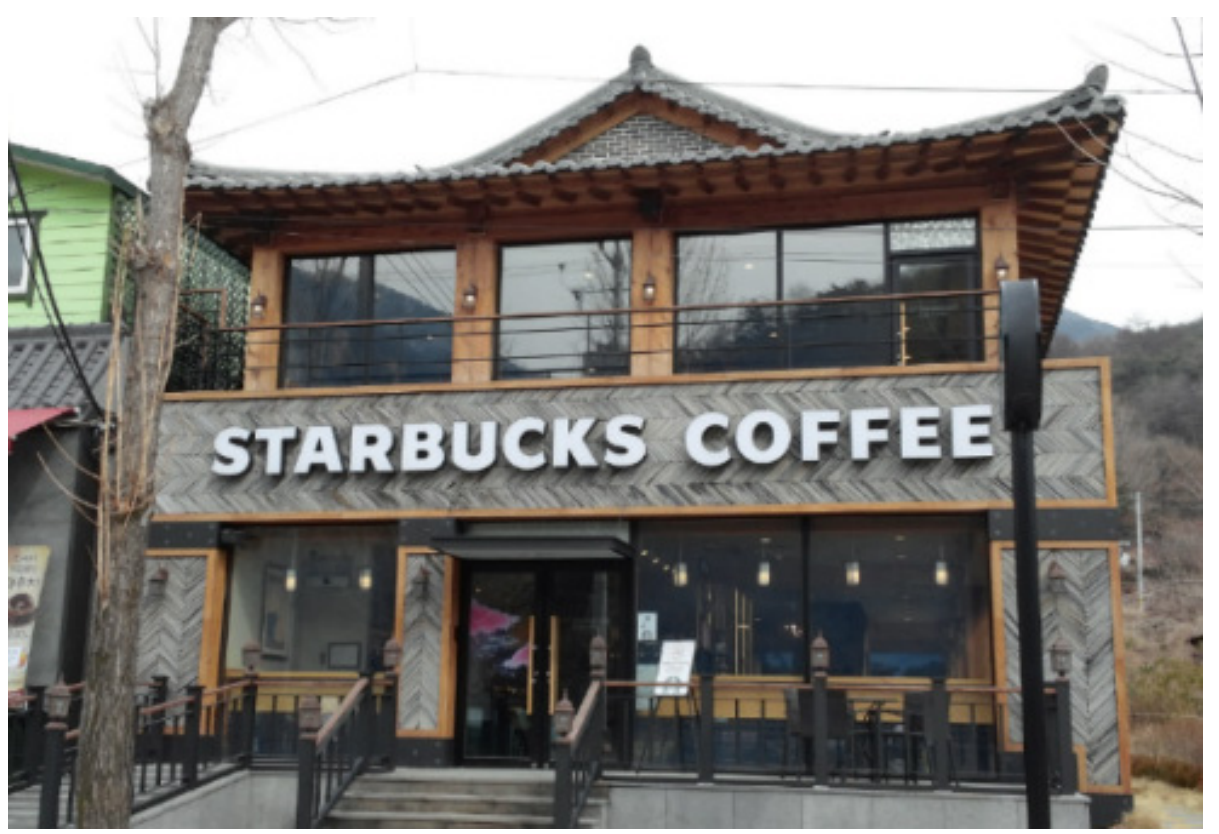

Figure 20. Starbucks in MungyeongSaejae.

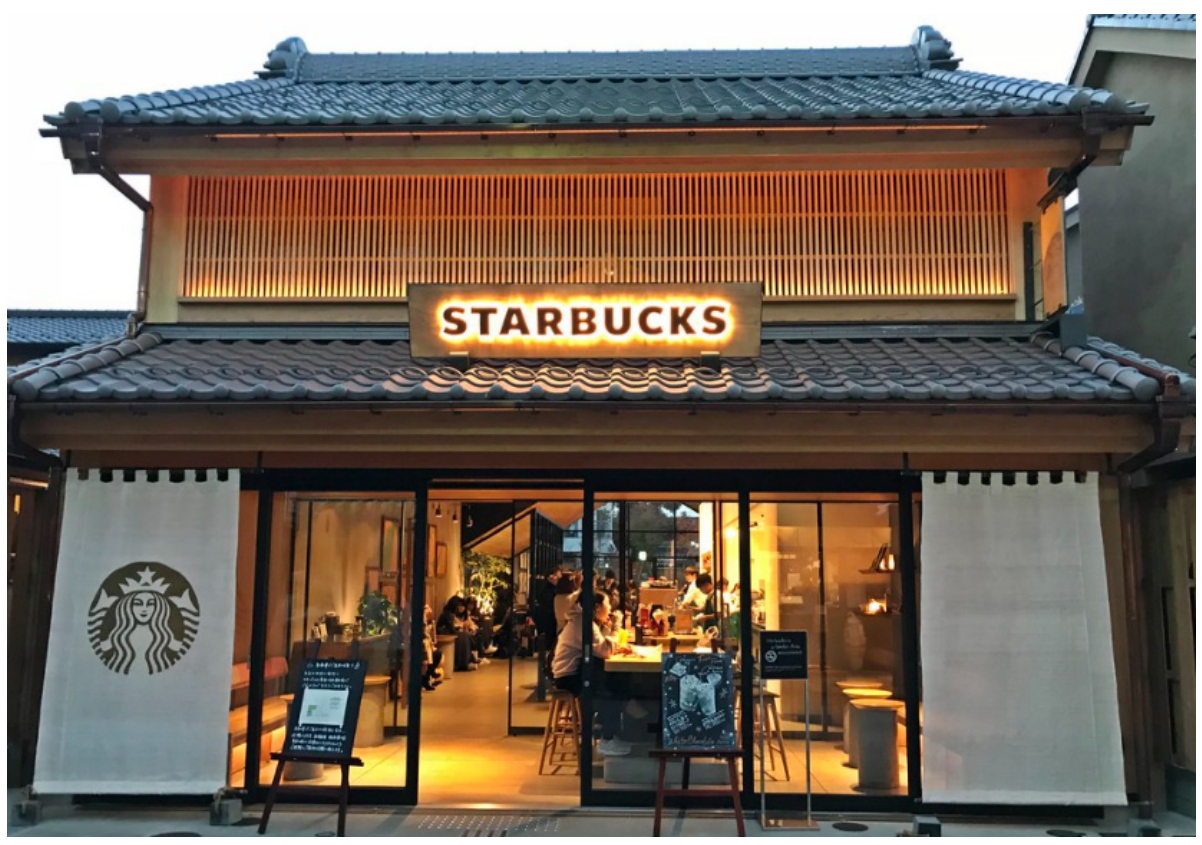

Figure 21. Starbucks in Kawagoe.

Blue Bottle pursues designs that blend well and coexist well with their particular surroundings. The architectural offices and spatial designers who were in charge of spatial designat Blue Bottle considered the following three things to be the most important: a space where consumers can wholly focus on the coffee, which is also most important; a space where consumers are welcomed; and a space that blends in with the region. Blue Bottlenot 
only looks at the space it is designing, but it is also fully conscious of how the store naturally blends into the surroundings and makes the neighborhood attractive (Figure 22). Even though the content may vary depending on the region, the symbolism and significance of each region are all reflected in the design. Blue Bottle Korea demolished two buildings and built one large building for its Seongsu store, using the most commonly seen architectural material (red bricks), so that it can coexist with the neighborhood (Figure 23). As Seongsudong is a region where the past, present, and future coexist, and where various generations who emphasize craftsmanship gather, the Blue Bottle store continuously emphasized the relationship with locals through coexistence with the neighborhood [72].

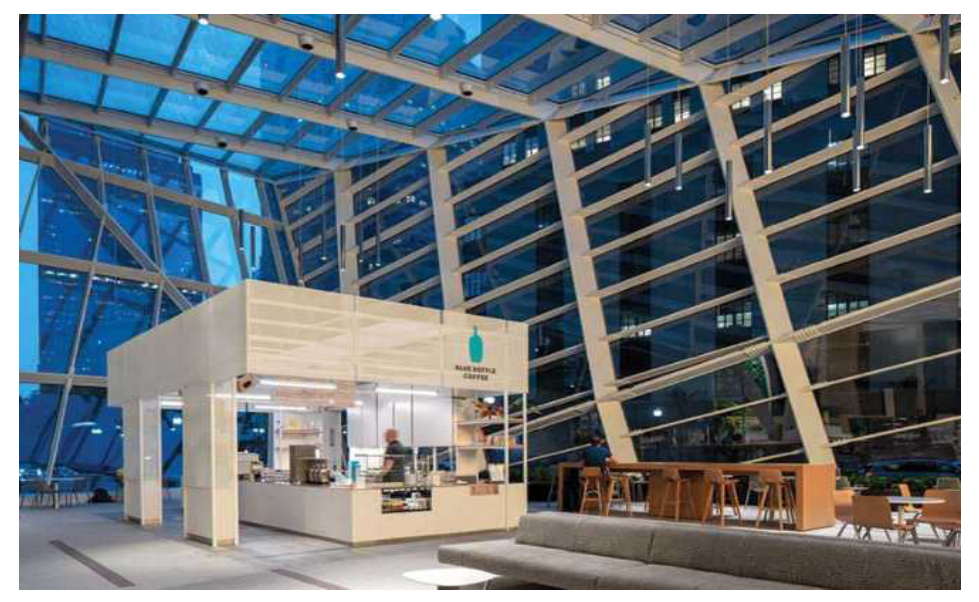

Figure 22. Blue Bottle, The Exchange, Boston [73].

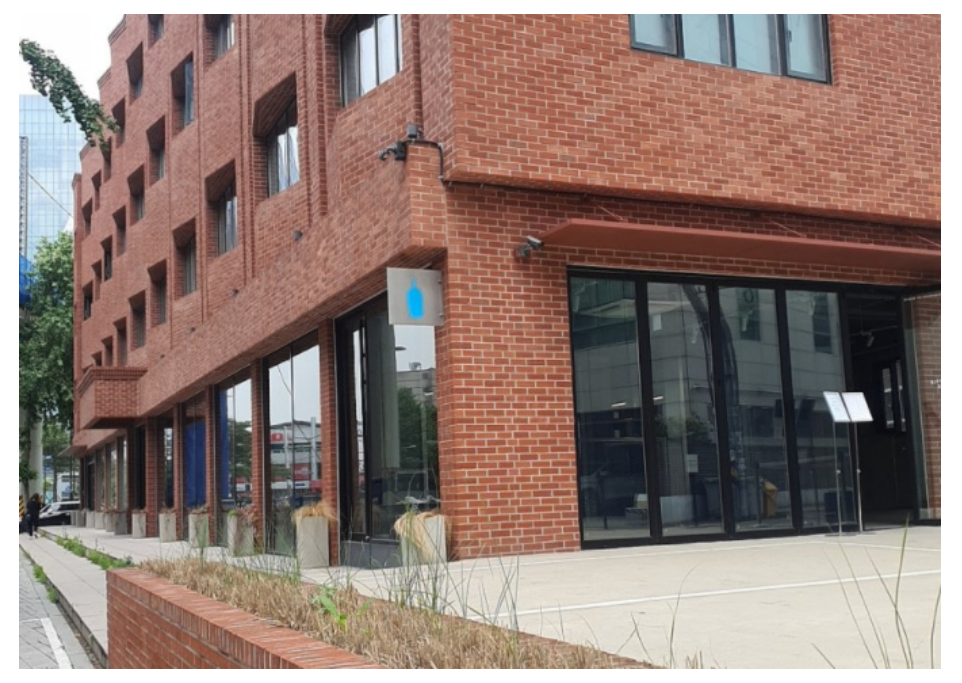

Figure 23. Blue Bottle in Seongsu.

\subsubsection{Space of Communication}

Starbucks, which has more loyal consumers than other brands, illustrates its storytelling well in its stores to impress the consumers with their experience, so that they are steadily satisfied and new consumers are enticed. The company is able to highlight the distinct characteristics of the region and create a space where consumers can experience using various senses. With its "selling space, not coffee" philosophy, Starbucks creates a comfortable space where consumers can stay for a while, thus giving meaning to the brand and planting emotional value. Furthermore, Starbucks is known for its extremely loyal consumers. For example, in its early days, Starbucks viewed young, highly educated and highly paid women as its "golden consumers" and targeted them as its primary consumers. It aimed to establish a sophisticated and elegant story. Accordingly, it located 
many of its stores in office districts and designed the spaces with more sophistication, while providing premium tea to differentiate itself from other coffee franchises. As a result, the number of young women who wished to partake of Starbucks' sophisticated and elegant brand increased, and the sales of MD products such as diaries and tumblers also sharply increased (Figure 24). By creating upgraded stores, such as "Starbucks Reserve" and "Reserve Roastery," Starbucks allowed consumers to feel like they were consuming not only a sophisticated space in the city but also their premium tea, just by being at these stores (Figure 25).

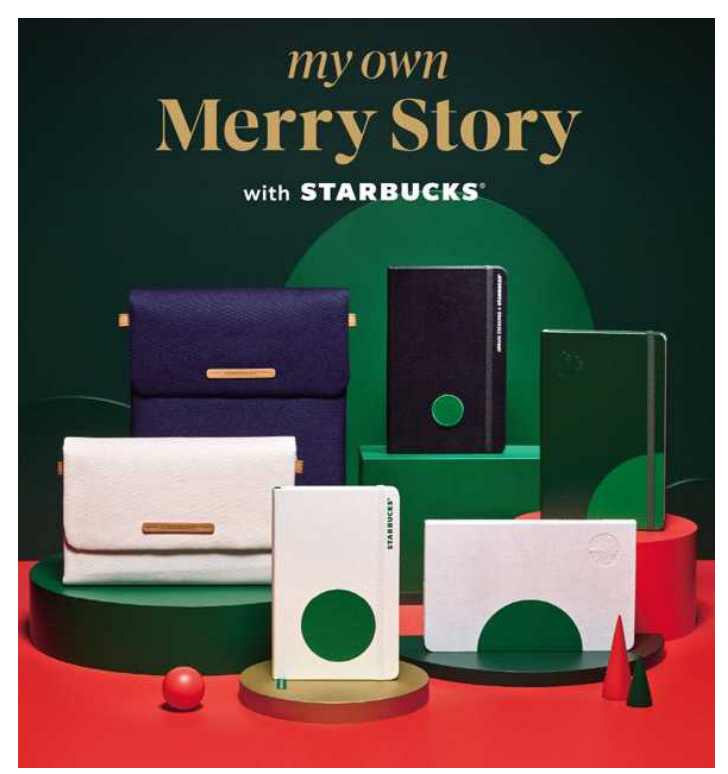

Figure 24. Starbucks 2021 Diary [74].

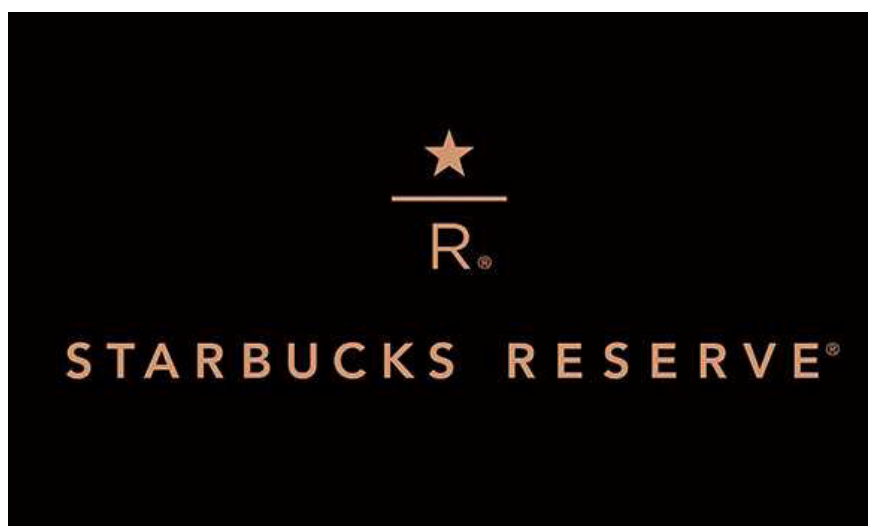

Figure 25. Starbucks Reserve logo [75].

The most attractive feature of Blue Bottle is its outstanding identity. The minimal yet distinctive design and visual identity leave a clear impression on the consumer, and definitively stands out on social media platforms such as Instagram and Facebook. Blue Bottle's online status and image are so strong that a single post on Instagram with Blue Bottle's space or coffee in the background can represent one's preferences and lifestyle in a charming way. The simplicity and intuitive elements seen in the design are also embodied in the spatial planning and consumer experience. Brand identity is also well-utilized in spatial design elements. For example, it was deliberately designed so that wooden tables, chairs, menus, and standing boards are uniformly used in the space, instead of colorful interior designs, to create a sense of psychological stability. This is accomplished while placing the relatively noticeable Blue Bottle logo in the center of the store so that it immediately pops into consumers' heads when they think of Blue Bottle (Figures 26 and 27). 
Furthermore, for Jo Nagasaka of Schemata Architects, who designed all of the Blue Bottle stores in Japan, space gives meaning through the interaction between stores, baristas, and consumers, thus, many newly interpretable spaces were left empty inside the stores. He is especially known for completing a space with emptiness. He prefers not to destroy and rebuild existing objects as much as possible, but rather to remodel and reinterpret them while leaving as much empty space as possible. Some spaces look incomplete, which stems from his hope that the brand's essence and the people fill the emptiness, and his specific design philosophy is in line with Blue Bottle's philosophy [76].

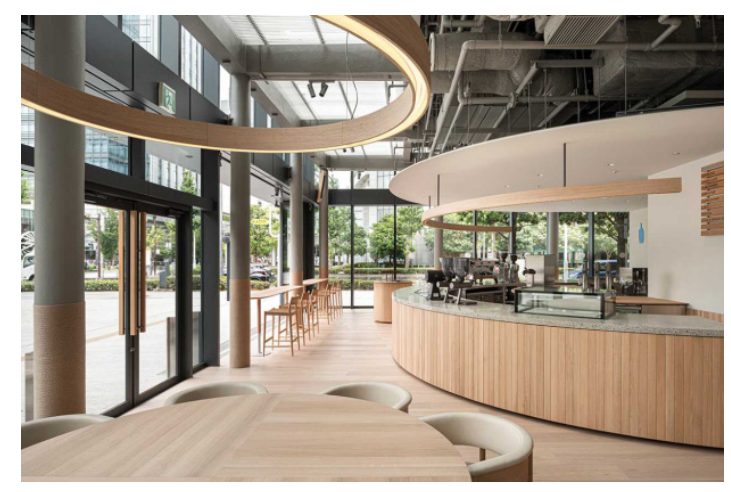

Figure 26. Blue Bottle in Yokohama [77].

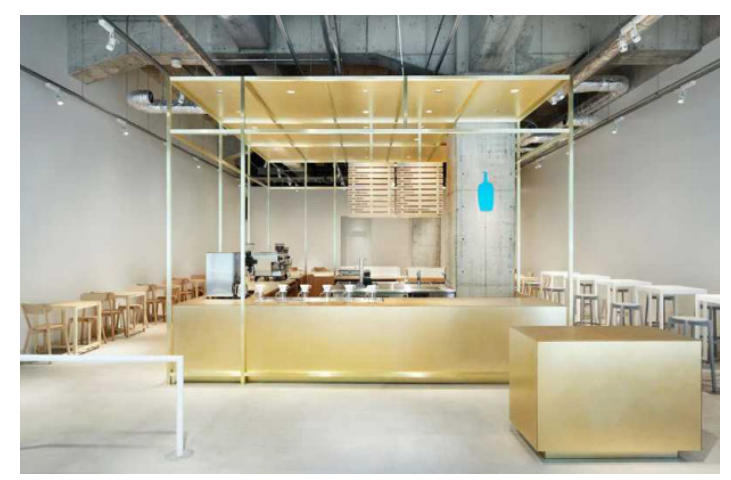

Figure 27. Blue Bottle in Kobe [78].

\subsubsection{Creation of Shared Value}

Starbucks creates sustainable value for the environment by recycling waste material or avoiding the use of disposable products. It is operating more than 1600 leadership in energy and environmental design (LEED)-certified stores in 20 countries around the world. Furthermore, driven by a wide shift to the circular economy, through the Resource Positive Project, it announced in January 2020 that it aims to reduce 50\% of its carbon emissions by 2030 , as well as $50 \%$ of its waste dumped into landfills from stores and manufacturing industries (Figure 28). It also stated that it currently preserves or replenishes $50 \%$ of the water used in its direct operations or coffee production. Additionally, Starbucks will be donating USD 10 million to developing countries over the next five years as a part of a water project via the water brand, Ethos Water (Figure 29). First introduced in 2002, Ethos helped provide clean water to children around the world through the sale of bottled water. It also built schools and medical facilities to help coffee farmers and provide an optimal environment for migrant coffee farmers [79]. Consequently, Starbucks has secured the branding that values such social values and created an environment where consumers can consume not only coffee but also these social values. 


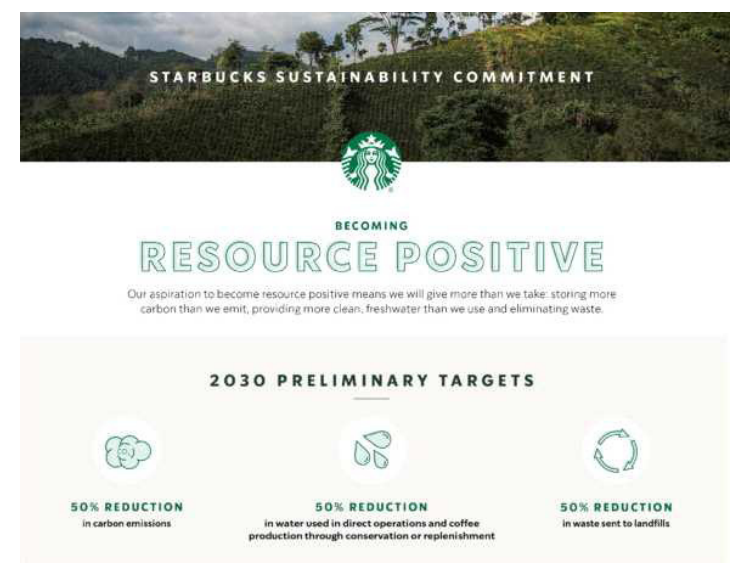

Figure 28. Starbucks Resource Positive Project [80].

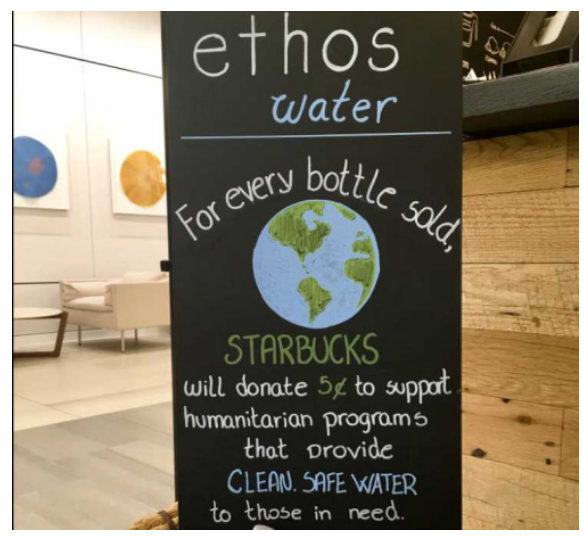

Figure 29. Starbucks Ethos Water Project [81].

The consumables used in Blue Bottle stores, such as cups, lids, straws, napkins, and filters, are compostable and renewable. Cups for hot beverages are double-walled paper cups lined with crystallized polylactic acid (CPLA), a plant-based bioplastic, and cups for cold beverages are lined with polylactic acid (PLA), an eco-friendly resin made from fuel extracted from corn starch, both of which are products made by World Centric. As for straws, all straws were replaced with paper straws certified by the Forest Stewardship Council (FSC), beginning in April 2019. This decision was made to create an environment for easy decomposition processing because the previous straws with PLA ingredients were not accepted for recycling or decomposition, according to the recycling standards of certain regions (Figure 30) [74].

In January 2018, Blue Bottle partnered with Miir, a company that provides clean water to one person for one year for each bottle of water sold; moreover, it launched the Travel Mug and Commuter Cup. For each purchased Travel Mug, which is a white stainless steel tumbler that emphasizes Blue Bottle's identity with a simply printed blue logo, or a purchased commuter cup, which is a Turkish blue outdoor cup, clean water is provided to a public elementary school in Addis Ababa, the capital city of Ethiopia. Each cup has a "give code" printed on its bottom, which can be entered on Miir's website to track where that cup's purchase ended up as drinking water. As such, Blue Bottle is building an image as a good company that has a positive impact on society through collaboration with social enterprises that make continuous donations to children in areas that suffer from hunger and poverty [78]. 


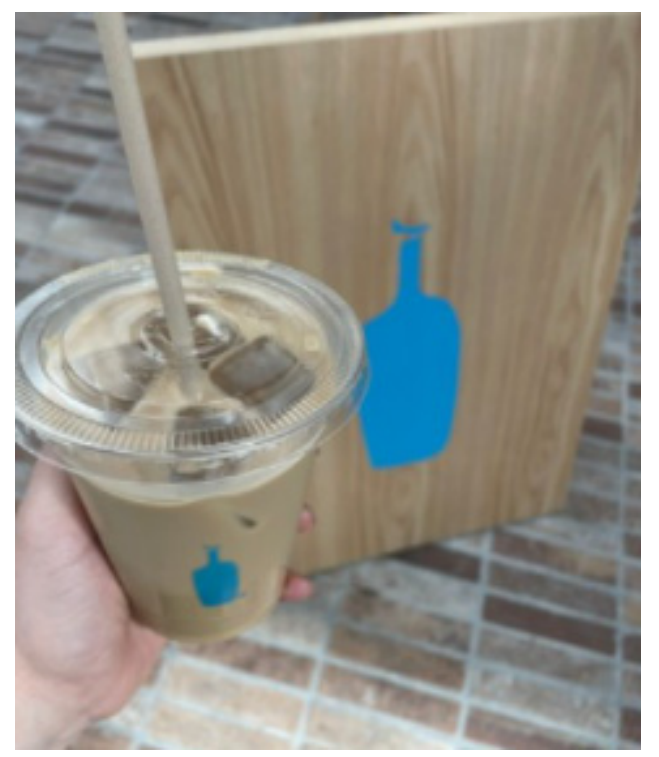

Figure 30. Blue Bottle straw made of bamboo fiber.

Blue Bottle also puts great effort into co-prosperity within the region. A co-prosperity agreement was signed between Seongdong-gu and Blue Bottle Coffee Korea for the creation of a jointly prosperous and communication-inclusive city when opening its first store in Seongdong-gu. In due course, Seongdong-gu and Blue Bottle Coffee planned various social contribution activities, such as barista education for residents and merchants, for the co-prosperous development of the local community. Correspondingly, Seongdong-gu supports and cooperates with Blue Bottle on matters necessary for regional co-prosperous development and social contribution activities promoted by Blue Bottle. The agreement also includes matters concerning the connection of human and material resources for the smooth operation of regional co-prosperous development programs (Figure 31).

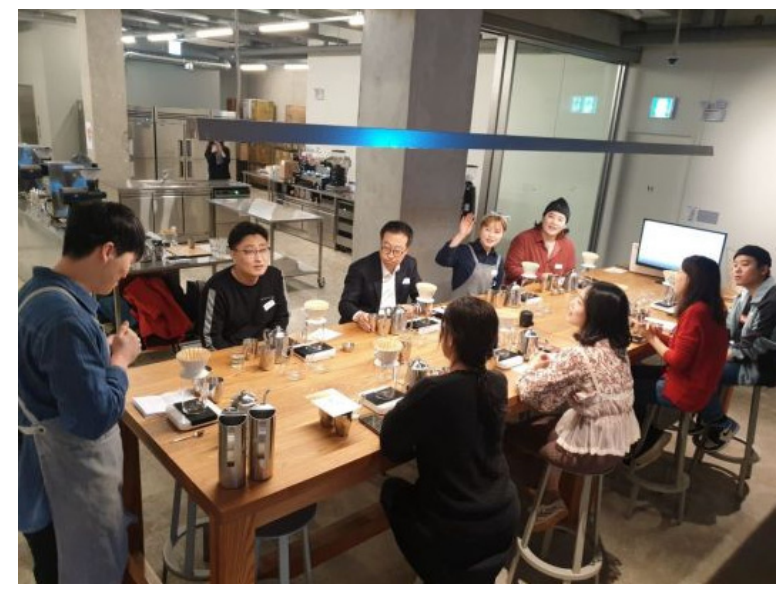

Figure 31. Blue Bottle Coffee Class with Seongdong-gu: regional co-prosperity between Blue Bottle and Seongdong-gu [82].

\subsubsection{Story Composition}

Starbucks at times creates stories through collaborations with other brands. The store in Ginza opened in July 2020 is a space created in collaboration with JINS, a specialized eyewear brand. With the motto, "A place you can concentrate best," an environment where it is easy to concentrate on the original tasks of business is created (Figure 32). Plants are placed strategically, and the sounds of nature are played in the background to create a comfortable atmosphere. Temperature and humidity, as well as lighting, are fine-tuned 
to the most optimal level; moreover, aromatic scents are utilized. However, the Starbucks Hana Biyori, located in Yomiuri Land near Tokyo, is filled with plants and flowers, and consumers can enjoy the flowers and the botanical garden all year round; even its signboard is made using plants (Figure 33).

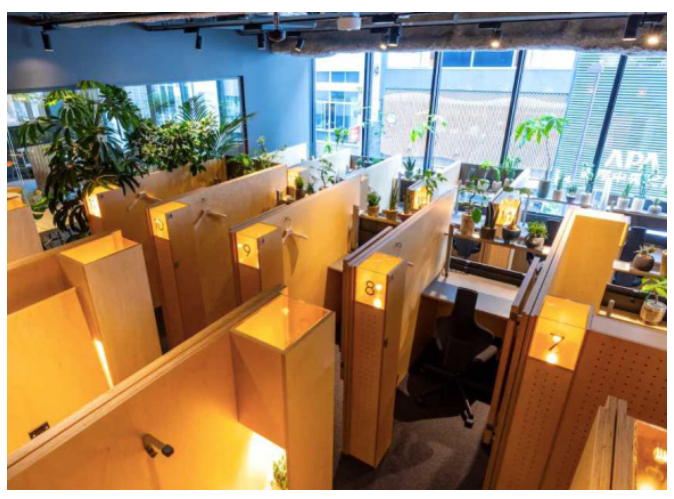

Figure 32. Think Lab, Starbucks collaboration store [83].

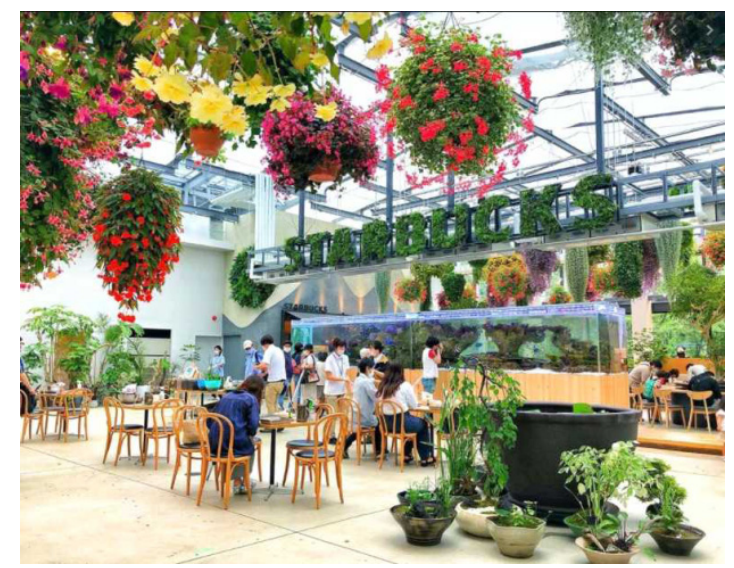

Figure 33. Hana Biyori, Starbucks collaboration store [84].

Starbucks' storytelling is especially highlighted in its Reserve Roasteries. A Starbucks Reserve Roastery is a space where Starbucks' capacity and values built over the years are focused, firmly expressing its identity and providing consumers with its culture. Each floor has a different concept, designed to satisfy the diverse consumer preferences, and provides ample content to the consumers, such as space, coffee, products, and food. As a result, the consumers are spending more time at Starbucks, during which they constantly consume and circulate Starbucks' cultural content. The Starbucks Reserve Roasteries represent Starbucks' core values and direction, and the company believes that the future of coffee shops lies with this concept.

Blue Bottle's storytelling can be largely divided into two. Blue Bottle is known to regard the space of its store as a theater, so the store space is decorated like a theatrical stage, regarding baristas as actors and consumers as the audience. The heights of coffee bars in all the stores are designed to stop below waist height, creating an environment in which all visual elements are excluded as much as possible, leaving only the baristas, consumers, and coffee on the stage. The coffee bar is designed so that the baristas, who are the protagonists, can move in the most optimal conditions; therefore, baristas move in the most optimal flow pattern during the entire process related to coffee, such as grinding beans, boiling water, hand-dripping, and washing tools. The baristas are able to weigh the coffee beans while simultaneously preparing the drip container, then are able to instantly grind the beans, immediately before making the coffee. The consumers, who are the audience, can stand in one spot and watch this entire process. One of the things Blue Bottle considers 
to be most important when preparing a store is illustrating a story in a space, to create strong storytelling. For example, the Blue Bottle store in Kiyosumi is a renovation of an abandoned factory that was once used as a wood warehouse (Figures 34 and 35). At the time of construction planning, the focus of spatial design was to not harm the shape of the building, because the preservation of the building that contains the memories and emotions of the local residents was a means for creating emotional solidarity with them. The writing on the concrete walls was preserved by intentionally ripping off the finishing, and the rusty inner walls and iron columns were also left as needed.

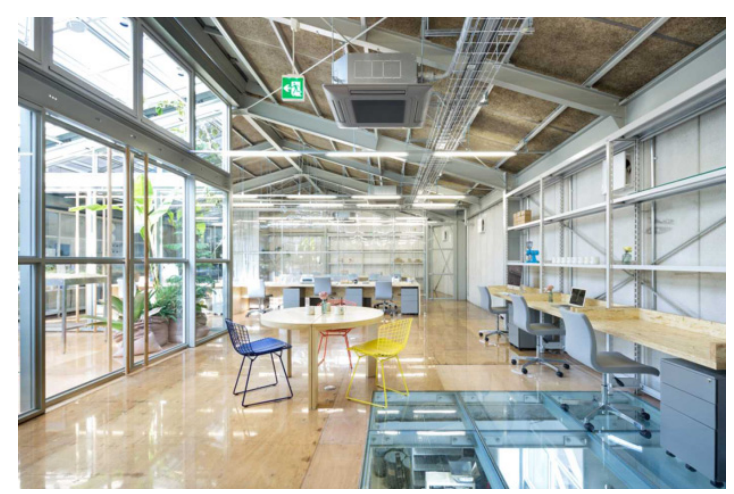

Figure 34. Blue Bottle in Kiyosumi [85].

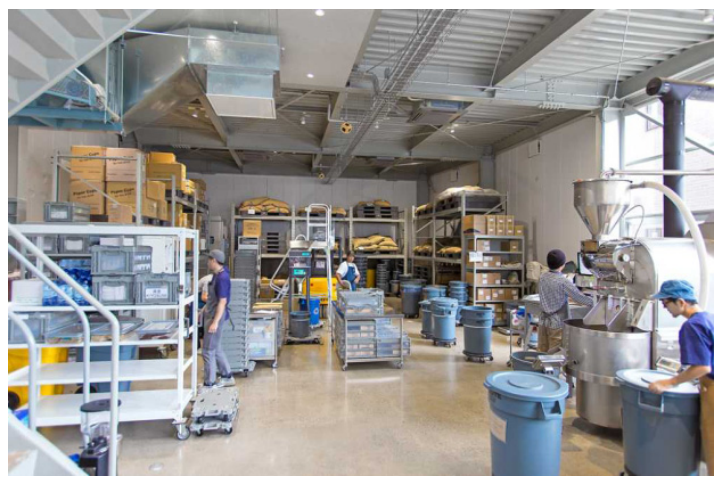

Figure 35. Blue Bottle in Kiyosumi.

\subsubsection{Space to Experience through the Five Senses}

Starbucks is well known for providing various concepts to satisfy the consumers' five senses. The furniture and interior decorations used at Starbucks are distributed directly from its headquarters. Even the music is played through its own music player. Additionally, to effectively deliver its distinct coffee flavor to consumers, Starbucks employees cannot use strong perfumes. As such, Starbucks endlessly pursues an evolutionary process in line with the culture and times, while never ceasing to try and preserve its symbolism. Starbucks' satisfaction of the five senses is especially noticeable at its Reserve Roasteries. The large Starbucks Reserve Roasteries have a big roasting machine installed in the center of the store, where the beans are directly roasted, allowing the consumers to experience it with their five senses. The roasting of the beans provides a complex experience, which triggers sight, while watching the beans get roasted; smell, from the strong coffee scent of the roasted beans; and hearing, when the beans are getting roasted and they move through the copper pipes (Figures 36 and 37). 


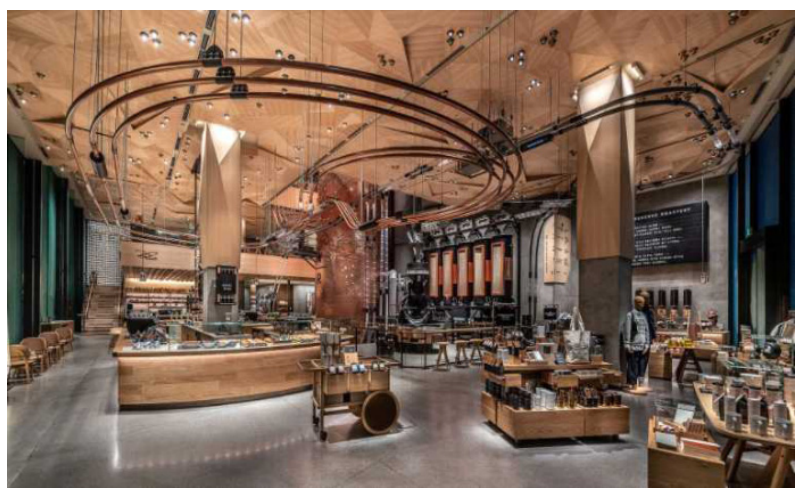

Figure 36. Starbucks Reserve Roastery in Seattle [86].

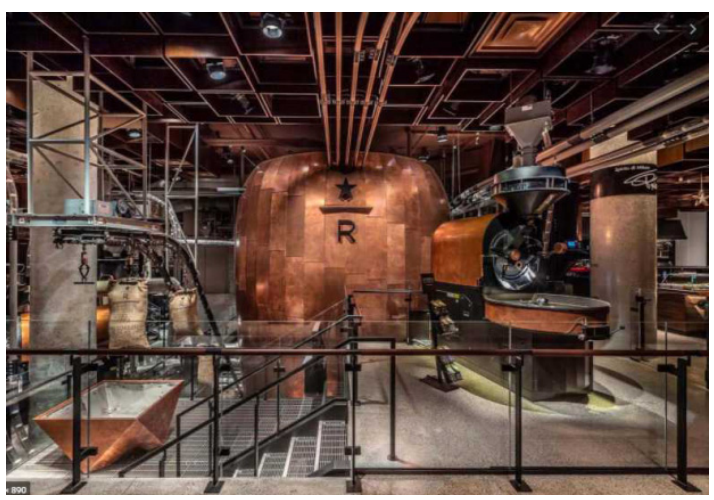

Figure 37. Roasting machine at Starbucks Reserve Roastery in New York [87].

Bryan Meehan, the chief executive officer (CEO) of Blue Bottle, said, "Designing the space of the stores is designing the experience. We always think about what our customers do in our stores and how they interact." As soon as you enter a Blue Bottle store, you are greeted with the magnificent smell of coffee, and the horizontal tables and baristas making coffee at the coffee bar come into sight. Moreover, by excluding elements that could act as obstacles for the consumer, Blue Bottle makes the consumers feel like they are on stage with only the barista and the coffee. Consumers can fully appreciate the barista's coffee extraction without any distractions, and wholly take in how their coffee is made (Figures 38 and 39). The rich scent of the coffee as it is being made, together with the carefully calculated volume of the background music, help the consumers better experience their coffee, which is at the core of Blue Bottle.

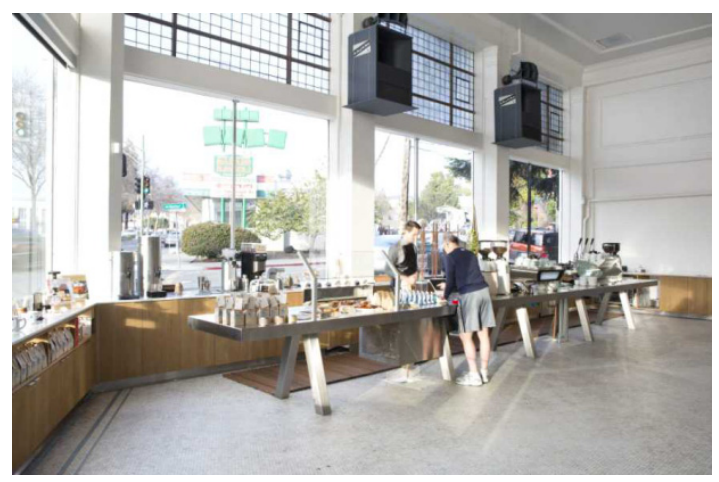

Figure 38. Hand drip coffee at Blue Bottle. 


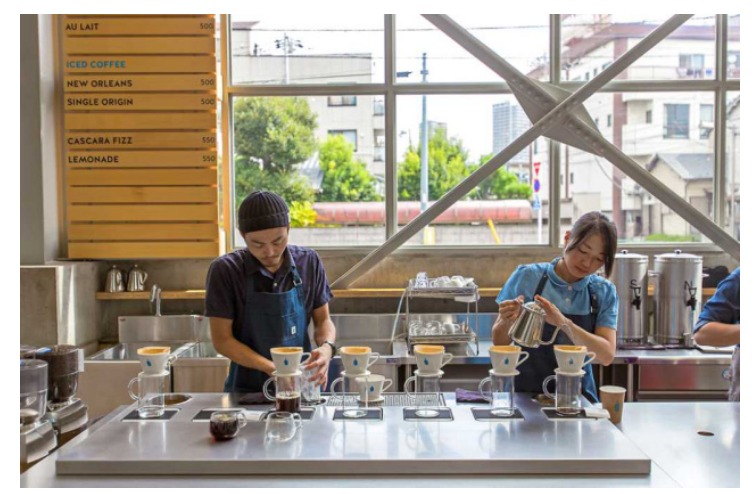

Figure 39. Coffee roasting at Blue Bottle.

The barista strikes up conversations with the consumers while making their coffee. They ask about their coffee preferences to try and reflect them in their coffee. This helps the consumers feel like they were indirectly involved in the making of their coffee. The Blue Bottle baristas give great performances based on their knowledge of coffee, seemingly unaware of the endless camera shutters, thereby providing consumers with a multisensory experience [78]. The smell and sound effects that come together with these visual images bring Blue Bottle's desired storytelling to life [74]. This is how Blue Bottle makes its storytelling a thorough consumer experience.

\section{Discussions}

Starbucks, the representative brand of the "second wave" of coffee, is very particular about its spatial design methods. Starbucks Coffee Korea has a store development team that is responsible for opening stores. This team searches for potential store locations, overlooks store leases, supervises interior design and construction, and takes charge of the maintenance and repair of facilities. There are 10 managers in charge of store development. Notably, each partner opens one store every month, which amounts to a total of 12 stores in one year. This manager who is responsible for opening Starbucks stores is called a Store Developer. They are mostly specialists in real estate, architecture, and interior design, and open up a wide range of stores. Starbucks also has Store Consultants, who analyze the efficiency of Starbucks stores and are responsible for the contract with the building's owner [88]. It takes at least six months for Starbucks to open a new store, during which time many parties, such as the design team, store development team, store developer, and store consultant, cooperate with regard to its opening. Korea is the only country, among the 77 countries that Starbucks entered in 2013, that has its own design team in Starbucks. Its efficient and systematic development system resulted in Starbucks' spatial design's ability to effectively and colorfully transmit the value of space to the consumers, to satisfy their various demands.

Blue Bottle has a different value of space from Starbucks in that it utilizes marketing. Specifically, the key to Blue Bottle's spatial design is the provision of perfect coffee. James Freeman, the founder of Blue Bottle, personally likes the Apple Store's spatial composition and flow. There are no objects in the Apple Store space that interrupt the consumer's line of sight, so that they can wholly focus on the products; furthermore, most of the furniture is minimal, and the spatial design of the store interior overall is restrained, simple, and intuitive. At the same time, it is designed to be friendly, open, and harmonious for the consumers-which is in line with Blue Bottle's core values. That is why Blue Bottle also boldly excluded all elements that are not related to coffee, so that the perfect cup of coffee is provided for the consumers. Colorful illustrations, or posters, objects, or furniture that may disrupt the line of vision are nonexistent in Blue Bottle stores, so that all eyes can be directed at the coffee. Even the background music volume, which should be blaring as in other coffee shops, is set to the minimum to create an environment where the consumers can fully concentrate on their coffee. 
As such, the marketing value of coffee franchises is derived from the characteristics of various spaces. Hence, the following sections summarize and reconstruct the content of Section 4, namely the six spatial marketing strategies of global coffee franchises-unique design, distinct local characteristics, space of communication, creation of shared value, story composition, and space to experience through five senses-according to the three characteristics of space, which are esthetic, interactive, and value.

\subsection{Unique Design Strategy Based on Esthetic Characteristics}

Importantly, coffee shops should basically have excellent spatial designs and functions. While additional meaning is in fact important, yet what must precede this is the unique design. Subsequently, this unique design must be able to effectively utilize the space. Excellent unique design not only secures the design of the coffee shop space but also creates the efficient utilization and overall ambiance of the space. For example, the outer walls of the coffee shop could be covered with vines, or a separate lawn may be created to add a natural element to the store, while the addition of a long coffee bar in a color that is in contrast to the entire store may provide an effective visual presentation and be used to maximize the utilization of a small space with an efficient flow. The ceiling of the store could be glass, to secure lighting and provide a sense of openness. Another approach would be tasteful lighting that goes well with the store ambiance and could be used to divide the space into zones, focusing attention on other parts of the space, such as the dessert display or the coffee bar, while customers can also enjoy the interior effect the lighting can bring, giving a sense of completion to the space.

\subsection{Distinct Local Characteristics Based on Esthetic Characteristics}

Coffee shops are greatly influenced by the local context. Because the distinct local characteristics are manifested as esthetic effects, if a space violates the atmosphere and "vibe" of the area, its design value may drop because of a sense of heterogeneity. For example, if the coffee shop is too sophisticated and decorated with an urban atmosphere in a neighborhood that is pastoral and lyrical, it is bound to repel consumers. However, if the coffee shop is to be located in a hanok village, the addition of traditional elements to the exterior and interior of the store to blend with its surroundings, or the usage of materials created from the local culture, will be able to secure the distinct regional characteristics. As such, the local identity and context should be studied and analyzed from the coffee shop's planning stages; additionally, the interior design should be able to harmoniously connect with the local context.

\subsection{Space of Communication Based on Interactive Characteristics}

The consumption of brands by consumers must be understood from the interaction perspective. When a brand presents a product to consumers with a special symbolic quality and identity through spatial marketing, the consumer consumes that product along with the brand identity and then gives and expresses value. Through such consumption behavior, the consumer becomes ever more strongly aware of the brand identity, and starts to think of themselves and the brand as one. Differentiated images can be communicated to consumers more effectively because they give visual clarity. One key example is the logo, which embodies the brand identity, as it reminds consumers of an image connected to the logo. A coffee shop with a simple and minimal identity minimizes furniture in the space and decorates the store with minimal color. Another example is upcycling. For coffee shops with the rediscovery of value through upcycling as their identity, the purpose of the previous space may be intentionally left throughout the space, or the original roof structure or clay walls may be intentionally exposed for the consumers to be able to feel the texture of the space. Lastly, coffee shops use logos in key locations in each space or use MD products to communicate with consumers. 


\subsection{Creation of Shared Value Based on Interactive Characteristics}

Modern consumers are increasingly observant and aware of the social contribution activities or the development of companies and brands. Consumption allows a brand's social contribution activities to be connected to the creation of shared value; sometimes it acts as a kind of indicator of their own presence and identity. If traces of a created shared value are found throughout the space, the consumers will feel the authenticity, share the value, and interact with the brand. If a coffee shop believes in sustainability, its space will be decorated with eco-friendly natural materials or will try to avoid using disposable products. Coffee shops that emphasize social solidarity will use furniture and objects made by public institutions; in contrast, coffee shops that place importance on interaction with animals will create a separate space for pets, or a space the consumer and their pet can experience together. If coffee shops can express emotional solidarity and share values with consumers through spatial marketing, consumers will bring a positive influence, such as vesting more meaning into their coffee shop visits, and consumption.

\subsection{Story Composition in Consideration of Value Characteristics}

A storyline with continuous thematic features is created to enhance memory learning about environments such as places and spaces. Memory is emphasized through a more vivid plot by breathing life into the space. Solid storytelling remains in the consumer's memory for a long time. If it is designed so that the consumer can see the coffee-making process or the coffee bean being roasted with the roasting machine in the coffee shop, a story about high-quality coffee is created. If the coffee shop wishes to connect the storytelling with a natural element, such as a garden or a nearby waterfall, it could design its outer wall with whole glass, or connect a bridge to where the natural element is located to secure it as part of the storytelling. If the coffee shop wants to present a retro-style type of storytelling, it could use retro-style menus or objects.

\subsection{The Value of Space for Experience, Utilizing the Five Senses}

The spaces for experience that awaken the senses and emotions start by stimulating the five senses. The five senses comprise sight, smell, hearing, touch, and taste. Sight is the easiest sense to utilize among the five senses, from the spatial marketing perspective, as it is the most intuitive and the fastest way to attract attention. Color can be used to attract great attention, or lighting could be used to create a dynamic atmosphere. Smell and taste create a synergistic effect and are the most effective in bringing back old memories. Rich smells make it easy to induce consumer purchases. Hearing is connected with other senses, thereby creating richer memories and feelings. The music in a space intrigues consumer curiosity or can deliberately adjust the consumer's tempo. Touch is felt through the skin, thus making it the sense most directly connected with the consumer. Experience through touch requires participation by the consumer, thus stimulating greater desires. Taste is developed through food and meals, and the taste of the food served in a space can be further highlighted through the placements of appropriate objects in the space. As such, the space for experience through the five senses combines elements of various senses to provide a new experience that has evolved into a multisensory dimension. When a coffee shop roasts and serves coffee directly in front of the consumers, the consumers will have indirectly experienced and visually participated in the process by merely watching the entire process. The scent and sound of coffee beans being roasted provide consumers with a richer experience. The smell of coffee in the store will also appeal to customers who have just entered the space. Such multisensory stimulus has a significant spatial marketing effect as it reminds consumers of the place where they initially felt the stimulation whenever they have related experiences. Furthermore, soft and comfortable music in the background makes consumers less burdened about staying in the space, and helps them wholly focus on the rich taste of coffee. 


\section{Conclusions}

Spatial design marketing to reflect the diverse individualities and values of the consumers is a very important branding strategy for global enterprises. It has particularly greater growth potential for coffee shops that provide a variety of cultural experience content, using coffee as a medium. This is because consumers who seek diversity of sensory input pursue their lifestyles through differentiated experiences, thus moving away from the uniform and standardized coffee shops. This study extracts the characteristics of modern consumers, and elements of spatial design marketing through literature review and prior studies, based upon which findings it proposes characteristics and strategies of spatial design marketing. Furthermore, the proposed strategies were studied through the global coffee franchises of Starbucks and Blue Bottle to examine how they were actually being implemented.

Characteristics of modern consumers identified through this study can be summarized as follows. Modern consumers, who live in an era saturated with information resulting from the development of digital devices such as smartphones, seek to express their individuality and identity and personally experience new things, as well as being particular about product quality and function. They also demand emotional solidarity with the brand, such as how the brand looks at the environment, or how well it blends in with the local culture. Furthermore, they prefer places and brands where they can feel the preciousness of their daily lives, and consume not only the product but also the culture connected to that product.

Elements of spatial design marketing were identified through the following keywords derived from prior studies on spatial marketing: the structural element that is the architectural and decorative parts of space; harmonious elements that fit in with the region or local context; the identity element that reflects brand identity into the space, to make an impression on the consumers; a solidarity element that connects brand value with what the consumers pursue; the developmental element that uses various themes by giving a space a story; and the experimental element that stimulates the consumer's five senses.

Such characteristics of the modern consumer and the elements of spatial design marketing were combined to derive the following three characteristics of spatial design marketing: esthetic, interactive, and value. Each characteristic was refined to present six strategies of spatial design marketing: unique design, distinct local characteristics, space of communication, creation of shared value, story composition, and space for experience through the five senses. Each strategy was analyzed through the examples of the global coffee franchises Starbucks and Blue Bottle, and the resulting implications are presented in the following section.

First, Starbucks uses only glass for its outer wall to maximize openness, and arranges the space and installs lighting so that MD and point-of-purchase (POP) stand out. Blue Bottle designs its space as simply and minimally as possible, as a space of emptiness rather than a space of fullness, so that the consumers can concentrate on the taste of coffee.

Second, Starbucks provides spatial design where tradition and the contemporary coexist, by utilizing the distinct local characteristics of the neighborhood the store will be located in. Blue Bottle pursues a design that can blend in and coexist with the surroundings, while also considering its relationship with the local residents.

Third, Starbucks' philosophy is to sell the space, not just coffee, and looks to create a space of communication where the consumers can stay comfortably for as long as they wish. Blue Bottle unified its tables, chairs, menu board, etc., with wooden materials rather than colorful interior design, and places its relatively noticeable blue bottle logo carefully to communicate with consumers.

Fourth, Starbucks avoids using plastic and uses upcycled products to create sustainable value for the environment. It also plays various social roles to help coffee farms. All consumables at Blue Bottle can be composted and recycled, and Blue Bottle launched a campaign that delivers bottled water to underdeveloped regions. 
Fifth, Starbucks delivers its own coffee culture to consumers with a variety of storytelling, through its Reserve Roasteries. Additionally, through collaboration with other brands, it allows consumers to experience new things other than coffee. Blue Bottle provides a story-type environment where baristas can focus on making coffee so that consumers can watch the process.

Sixth, Starbucks provides a rich and complex experience that stimulates the five senses of consumers with not only its selected coffee scents and music but also the installation of large roasting machines. Blue Bottle stimulates the five senses of consumers through the process of making coffee, by arranging the space like a theater stage. With the horizontal bar table acting as the stage, the space is designed so that it feels like only the barista, consumer, and coffee are on the set.

The spatial marketing implications of the two brands researched through these findings are as follows. Starbucks is implementing a space marketing strategy to represent diverse and complex cultures through coffee as a medium. As a result, Starbucks has created an environment where consumers can spend a long period in the store and consume various products provided by Starbucks. In other words, Starbucks analyzes space as a "major factor in consumption", with space marketing for all services and experiences related to coffee. Blue Bottle, on the other hand, offers space marketing strategies to focus fully on coffee. Bluebottle excluded the distraction from coffee as much as possible and kept consumers' attention away from anything other than coffee through minimal and restrained spatial design. In other words, Blue Bottle provides space for customers to enjoy the best-quality coffee as a marketing strategy, and analyzes space as a "background of consumption."

This study is meaningful as it derived three spatial marketing characteristics and six of its strategies that can enhance the spatial value of coffee shops and the experiential value of consumers. This was accomplished through an approach focusing on Starbucks and Blue Bottle, the most representative global coffee franchises. Moreover, the presented spatial design marketing strategies are not only applicable to coffee franchises but also to various commercial spatial design fields, and our findings are expected to be used as a business methodology that can satisfy the needs of modern consumers and increase the unique value of a brand.

Author Contributions: This paper was produced through teamwork. J.-E.K. and E.-S.P. jointly designed the research. J.-E.K. developed the methodology and the conceptual design, carried out the investigation, and drafted the original manuscript, and E.-S.P. analyzed the data and improved the manuscript. All authors have read and agreed to the published version of the manuscript.

Funding: This research received no external funding.

Institutional Review Board Statement: Not applicable.

Informed Consent Statement: Not applicable.

Conflicts of Interest: The authors declare no conflict of interest.

\section{References}

1. Hong, S.Y. Space Marketing; Samsung Economic Research Institute: Seoul, Korea, 2007.

2. Han, H.R. A Case Study on Complex Cultural Spaces of Companies from a Space Marketing Perspective. Master's Thesis, Yonsei University, Seoul, Korea, 2015.

3. Kim, I.S. A Study on Space Positioning Comparison in Consideration of Space Marketing. Master's Thesis, Sejong University, Seoul, Korea, 2016.

4. Schmitt, H. Experiential Marketing: How to Get Customers to Sense, Feel, Think, Act, and Relate to Your Company and Brands; Free Press: Washington, DC, USA, 1999.

5. Verdil, A. Transformation of Space Behavior Relation. In Proceedings of the 7th Space Syntax Symposium, Stockholm, Sweden, 8-11 June 2009.

6. Kother, P.; Keller, K.; Jo, H.; Hong, S.; Sin, J.; Kim, D. (A) Framework for Marketing Management, 5th ed.; Pearson Education: London, UK, 2012. 
7. Pak, S.S.; Yi, S.H. The study on the concept of space design marketing and the background of its emergence. J. Korea Des. Forum 2008, 21, 107-116.

8. Kim, J.Y. Space Marketing; Three Chairs: Seoul, Korea, 2020.

9. Kotler, P. Market 3.0; Wiley: New York, NY, USA, 2010.

10. Trout, J. Business Strategy; McGraw-Hill Education: NewY ork, NY, USA, 2004.

11. Dutka, A. AMA Handbook for Customer Satisfaction; NTC Business Books: Lincolnwood, IL, USA, 1994.

12. Schullz, D.; Tannenbaum, S.; Lauterborn, R. Integrated Marketing Communications; NTC Business Books, a Divisionof NTC Publishing Group: Lincolnwood, IL, USA, 1993.

13. Trout, J.; Rivkin, S. The Power of Simplicity; McGraw-Hill Education: New York, NY, USA, 2000.

14. Wake, W. Design Paradigms: A Sourcebook for Creative Visualizations; Wiley: New York, NY, USA, 2006.

15. Westbrook, R.; Black, W. A Motivation-Based Shopper Typology. J. Retail. 1985, 61, 78-103.

16. Gad, T. Customer Experience Branding; Kogan Page: London, UK, 2019.

17. Kotler, P. Atmospherics as a Marketing Tool. J. Retail. 1973, 49, 49-64.

18. Holbrook, M.; Hirschman, E. The Experimental Aspects of Consumption: Consumer Fantasies, Feeling and Fun. J. Consum. Res. 1982, 9, 132-140. [CrossRef]

19. Ha, E.K. A Study on the Flow Structure in User Experience with Digital Media. Ph.D. Thesis, Hongik University, Seoul, Korea, 2010.

20. Tuan, Y. Space and Place; University of Minnesota Press: Minneapolis, MN, USA, 1995; 124p.

21. Koolhass, R. Projects for Prada; Part 1; Fondazione Prada: Milan, Italy, 2001.

22. Kim, J.S. Experiential Design of Three-Dimensional Space Approach with Pleasure Value rather than Practical Value; Dongah Business Review: Seoul, Korea, 2012.

23. Lobaugh, K.; Stephens, B.; Simpson, J. Consumers are Changing; Deloitte Insights: New York, NY, USA, 2019.

24. Tuan, Y. Topophilia: A Study of Environmental Perception, Attitudes, and Values; Columbia University Press: New York, NY, USA, 2011.

25. Lefebvre, H. (La)Production de L'espace; Wiley-Blackwell: New York, NY, USA, 2011; pp. 1-605.

26. Relph, E. Place and Placelessness; SAGE Publications Ltd.: Thousand Oaks, CA, USA, 2017; pp. 1-452.

27. Kim, N.Y. 2020 Selling Lifestyle Trends; Hans Media: Seoul, Korea, 2020.

28. Casey, E. The Fate of Place; University of California Press: San Diego, CA, USA, 2016; pp. 1-928.

29. Schroer, M. Raume, Orte, Grenzen; Suhrkamp Verlag KG: Berlin, Germany, 2010; pp. 1-415.

30. Malpas, J. Heidegger's Topology: Being, Place, World; MIT Press Series, A Bradford Book; MIT Press: Cambridge, MA, USA, 2006.

31. Cresswell, T. Place: A Short Introduciton; Wiley-Blackwell: New York, NY, USA, 2016; pp. 1-264.

32. Hwang, B.Y. The new topic of marketing 'experience and experience'. Digital Contents 2006, 157, $114-117$.

33. Kern, S. The Culture of Time and Space; Harvard University Press: Cambridge, MA, USA, 2013; pp. 1-766.

34. McCracken, G. Culture and Consumption, New Approaches to the Symbolic Character of Consumer Goods and Activities; Indiana University Press: Bloomington, IN, USA, 1988.

35. Kim, Y.K. Culture Consumption and Image; HS Adzine: Seoul, Korea, 2010.

36. Massey, D. For Space; SAGE Publications Ltd.: New York, NY, USA, 2016; pp. 1-400.

37. Doering, J. Spatial Turn; German Edition: Berlin, Germany, 2015; pp. 1-630.

38. Jeffries, S. It's the Third Wave of Coffee! The Guardian, 16 March 2009.

39. Gold, J. The 10 Best Dishes of 2008. LA Weekly. December 31. \& Jonathan Gold. 2008. Tierra Mia Explores Coffee for the Latino Palate. LA Weekly, 20 August 2008.

40. Skeie, T.R. Norway and Coffee. The Flamekeeper, 11 October 2003.

41. CoffeetalkMAGAZINE. The Future of Specialty Coffee and the Next Wave. CoffeetalkMAGAZINE, 23 January 2016.

42. Kim, M.S. The Wave of Coffee Markets; Terarosa Library: Gangwondo, Korea, 2018.

43. Gold, J. La Mill: The Latest Buzz. LA Weekly, 19 December 2008.

44. Wallace, H. Do I Detect a Hint of ... Joe? The New York Times, 29 May 2008.

45. Dicum, G. Los Angeles: Intelligentsia. The New York Times, 9 March 2008.

46. Reuters. Peet's Rides Coffee's 'Third Wave' with Stake in Intelligentsia. Reuters, 30 October 2015.

47. LA Times. Trish RothgebCoined 'Third Wave'-And is Now Looking Toward Coffee's Future. Los Angeles Times, 4 October 2019.

48. Perfect Daily Grind. What is Third Wave Coffee? Perfect Daily Grind: Crowborough, UK, 2019.

49. Rugolo, J. The Waves of Feminism \& Coffee. Tamper Tantrum, 18 October 2017.

50. Zwahlen, C. Coffeehouse Serves the Latino Community. Los Angeles Times, 15 September 2008.

51. Scattergood, A. Artisans of the Roast. Los Angeles Times, 25 October 2006.

52. Stumptown Coffee Roasters. Coffee Shop Locations. Stumptown Coffee Roasters, 13 December 2015.

53. Bluebottlecoffee. The first Blue Bottle Statement. 2021. Available online: https://www.bluebottlecoffee.com (accessed on 10 May 2021).

54. Lee, G.Y. A Study on the Expressive Characteristics of Emotional Design in the Fashion Brand Flagshop form the Viewpiont of Space Marketing. Master's Thesis, Kookmin University, Seoul, Korea, 2019.

55. Chae, H.J. A Study on the Expression of five-Sense and Affective Design in Cafe Space. Master's Thesis, Hongik University, Seoul, Korea, 2019. 
56. Lee, S. A Study on Design Elements of Interior Space by Expressing Sensation in Sensibility Cafe Space. Master's Thesis, Hanyang University, Seoul, Korea, 2017.

57. ArchDaily. Israel Coffee Shop Project Statement. 2018. Available online: https://www.archdaily.com (accessed on 9 May 2021).

58. Digjapan. Cafe Slow in Kokubunji Statement. 2001. Available online: https://digjapan.travel/en/ (accessed on 11 May 2021).

59. ArchDaily. Gallery of Maxim Plant Statement. 2018. Available online: https:/ / www.archdaily.com (accessed on 11 May 2021).

60. Swiss Giraffe. A Cup of Coffee and 3D Printing at Makers Cafe London Statement. 2018. Available online: https://www. swissgiraffe.com/ (accessed on 11 May 2021).

61. Chun, J.W.; Kim, J.E. A Study on the Space Design of Coffee Shops from the View of Space Marketing. J. Korea Instit. Spatial Des. 2020, 15, 469-482.

62. Kim, T.H.; Kim, K.C.; Kim, J.E. A Study on the Visiting Cyclic Path of Interactive Space Reflecting Characteristics of Digital Native. Korean Instit. Interior Des. J. 2020, 29, 19-22. [CrossRef]

63. Pittawat, P.; Kim, J.E.; Kim, K.C. A Study on Phygital Retail Store for Create Customer Experience Space. J. Basic Des. Art 2020, 21, 489-504.

64. Kim, J.Y. Space Blending; Three Chairs: Seoul, Korea, 2020.

65. Kang, K.J. Brand Identity Management; Fashion Insight: Seoul, Korea, 2018.

66. Lee, K.M.; Jung, E.A. We Sell Our Tastes; Some \& Partners: Seoul, Korea, 2019.

67. Wang, Z. Starbucks Confident on China Turnaround. Chinadaily, 11 July 2018.

68. Byjeanne. Starbucks Seasonal Menu Statement. 2013. Available online: https:/ / byjeanne.com/ (accessed on 11 May 2021).

69. Magazine, B. Bluebottle Coffee; Magazine B: Seoul, Korea, 2019.

70. ArchDaily. Blue Bottle Roppongi cafe Statement. 2018. Available online: https:/ /www.archdaily.com (accessed on 10 May 2021).

71. Jung, H.S. Selling Lifestyle; bookbyPUBLY: Seoul, Korea, 2019.

72. Oh, S.H. Coffee Experience Stage, Store Design; Design House: Seoul, Korea, 2018.

73. Blumenthal, R.L. Boston's Second Blue Bottle Coffee Opens this Weekend. Eater Boston, 8 May 2018.

74. Han, K.J. Starbucks Diary and Crossbag End of Year Event. Chosunmedia, 26 October 2020.

75. Starbucks Reserve. Starbucks Reserve Logo Statement. 2021. Available online: https://dev1.starbucksreserve.com/en-us (accessed on 7 May 2021).

76. Yang, D.Y. I've Been to Bluebottle; Three Chairs: Seoul, Korea, 2018.

77. Hypebeast. Yokohama's Blue Bottle Coffee Cafe Is a Vibrant Medley of Natural Materials Statement. 2020. Available online: https:/ / hypebeast.com/ (accessed on 10 May 2021).

78. Ishinomaki Laboratory. Blue Bottle Coffee NAKAMEGURO Café Statement. 2016. Available online: https://ishinomaki-lab.org/ (accessed on 10 May 2021).

79. Michelli, J. Starbucks Experience Marketing; UX Review: Seoul, Korea, 2018.

80. Jennifer Warnick. 5 Things to Know about Starbucks New Environmental Sustainability Commitment Statement. 2020. Available online: https:/ / stories.starbucks.com/ (accessed on 8 May 2021).

81. Starbucksmelody. Ethos Water California Starbucks Statement. 2012. Available online: http://www.starbucksmelody.com/ (accessed on 10 May 2021).

82. Kim, D.P. Seongdong-gu, Blue Bottle Coffee Class Operation. Shinaibo, 8 December 2019.

83. Share. New Starbucks in Tokyo Features Dedicated Space for Focus Statement. 2020. Available online: https://stories.starbucks. $\mathrm{com} /$ (accessed on 8 May 2021).

84. Share. Yomiuriland's Hana-Biyori Has Flowers, Projection Mapping, Otters, and Japan's First Botanical Garden Starbucks statement. 2020. Available online: https:/ / www.japankuru.com/en/ (accessed on 8 May 2021).

85. Cho, S.E. Starbucks is Confident about the Future of Offline; Brunch: Seoul, Korea, 2019.

86. Starbucks Reserve. Seattle Roastery Statement. 2014. Available online: https://dev1.starbucksreserve.com/en-us (accessed on 7 May 2021).

87. Muller, L. Starbucks Reserve Roastery in New York Offers a 360-Degree Walk-Around View of the Roasting Process. c3diz, 16 May 2019.

88. Joo, H.S. Starbucks, We're Selling Space; RH Korea: Seoul, Korea, 2017. 